1 Title: Liquid-liquid phase separation facilitates the biogenesis of

2 secretory storage granules

3 Authors: Anup Parchure ${ }^{1}$, Meng Tian ${ }^{1}$, Cierra K Boyer ${ }^{2,3}$, Shelby C Bearrows ${ }^{2,3}$, Kristen E Rohli ${ }^{2,3}$,

4 Jianchao Zhang ${ }^{4,5}$, Bulat R Ramazanov ${ }^{1}$, Yanzhuang Wang ${ }^{4,5}$, Samuel B Stephens ${ }^{2}$ and Julia $^{2}$

5 von Blume ${ }^{1 *}$

\title{
6 Affiliations:
}

7 1Department of Cell Biology, Yale University School of Medicine, New Haven, CT, USA

8 2Fraternal Order of Eagles Diabetes Research Center, Departments of Pharmacology and

9 Neuroscience and Internal Medicine ${ }^{3}$, Division of Endocrinology and Metabolism, University of

10 lowa, lowa City, IA, USA.

$11{ }^{4}$ Department of Molecular, Cellular and Developmental Biology, University of Michigan, Ann

12 Arbor, MI, USA

13 5Department of Neurology, University of Michigan School of Medicine, Ann Arbor, MI, USA.

14

$15{ }^{*}$ Corresponding author E-mail: julia.vonblume@yale.edu, Phone: +1 2037372746

16

17

18

19

20

21 


\section{Abstract}

25 Insulin is a key regulator of human metabolism, and its dysfunction leads to diseases such as

26 type 2 diabetes. It remains unknown how proinsulin is targeted from the trans-Golgi network

27 (TGN) to secretory storage granules as no cargo receptor has been identified. Chromogranin

28 proteins (CGs) are central regulators of granule biosynthesis, and it was proposed that their

29 aggregation is critical for this process. However, the molecular mechanism by which these

30 molecules facilitate sorting at the TGN is poorly understood. Here, we show that CGs undergo

31 liquid-liquid phase separation (LLPS) at low $\mathrm{pH}$ independently of divalent cations, such as

32 calcium. Liquid CG condensates, but not aggregates, recruit and sort proinsulin and other

33 granule-destined cargo molecules towards secretory granules. Cargo selectivity is independent

34 of sequence or structural elements but is based on the size and concentration of the client

35 molecules at the TGN. Finally, electrostatic interactions and the N-terminal intrinsically disordered

36 domain of chromogranin B facilitate LLPS and are critical for granule formation. We propose that

37 phase-separated CGs act as a "cargo sponge" within the TGN lumen, gathering soluble client

38 proteins into the condensate independently of specific sequence or structural elements, facilitating

39 receptor-independent sorting. These findings challenge the canonical TGN sorting models and

40 provide insights into granule biosynthesis in insulin-secreting $\beta$-cells.

41

42 One sentence summary

43 Liquid Chromogranin condensates recruit cargo molecules at the TGN for their delivery to 44 secretory storage granules. 
bioRxiv preprint doi: https://doi.org/10.1101/2021.12.22.472607; this version posted December 23, 2021. The copyright holder for this preprint (which was not certified by peer review) is the author/funder, who has granted bioRxiv a license to display the preprint in perpetuity. It is made available under aCC-BY-NC-ND 4.0 International license.

\section{$46 \quad$ Keywords}

47 Proinsulin, sorting and secretion, regulated secretion, trans-Golgi Network, LLPS, pH, zinc,

48 calcium, secretory granule biosynthesis

49

50

51

52 


\section{Main text}

\section{Introduction}

55 Secretory proteins control human metabolism and physiology, and their mistargeting causes several diseases, including type 2 diabetes (T2D), neurological disorders, and cancer $(1,2)$.

57 Secretory proteins are synthesized in the endoplasmic reticulum (ER) before being loaded into vesicular carriers for transport to the Golgi apparatus (3-6). Eventually, these proteins reach the trans-Golgi network (TGN) and are sorted and packaged into specific carriers for transport to their final destinations, including the cell surface, endolysosomes, and secretory storage granules (7-

61 10). Cargo receptors targeting soluble proteins to the cell surface or secretory granules in

62 specialized cells have not been identified and it remains an enigma how these non-membrane

63 attached molecules are sorted and targeted in the $\operatorname{TGN}(9,11)$.

64 Understanding the sorting and targeting of proteins from the TGN to secretory storage granules

65 in professional secretory cells such as insulin-secreting pancreatic $\beta$ islets remains a challenge

66 in the field (12-15). Secretory storage granules are cytosolic storage structures found in

67 endocrine, exocrine, and neuronal cells. Early electron microscopy imaging has shown that

68 secretory granules contain an electron-dense core, and that condensation occurs in sequential

69 steps starting in the TGN (16-18). Soluble proinsulin is synthesized in the ER and transported to

70 the TGN to be sorted and packaged into immature secretory storage granules (ISGs) $(19,20)$. In

71 ISGs, proinsulin is proteolyzed to mature insulin by the protein convertases $\mathrm{CPE}, \mathrm{PC} 1 / 3$ and PC2

72 (21), after which mature insulin forms hexameric crystals in the presence of zinc $(21,22)$. In

73 response to nutrient stimuli, mature SGs are mobilized to fuse with the plasma membrane and

74 deliver insulin to the bloodstream, a process called regulated secretion (23). While there is

75 considerable knowledge of the processing of proinsulin in SGs, it is unclear how proinsulin is

76 sorted into secretory granules at the TGN (24). Importantly, morphometric studies of human T2D

77 islets have shown that the volume density of total mature insulin granules in $\beta$-cells is significantly 
78 diminished, and that this pool size correlates with the diminished magnitude of the glucose-

79 stimulated insulin secretion response (25).

80 Pulse-chase experiments have shown that dense core structures emerge from the Golgi to form

81 ISGs and that granule content further condenses upon reaching the mature secretory granule (18,

82 26). Granin proteins, including chromogranin A (CHGA, CGA) and B (CHGB, CGB), provide a

83 selective and condensing power for granule-targeted cargo molecules. Genetic and biochemical

84 studies have shown that chromogranins (CGs) are fundamental regulators of granule biosynthesis

85 (27-29). Intriguingly, ectopic expression of either CGA, CGB or other granin family members

86 induces SG-like structures in non-secretory cells (28, 30-32). Experiments utilizing purified

87 proteins or crude extracts of adrenal or pituitary glands showed that these molecules aggregate

88 at acidic $\mathrm{pH}(5.5)$ and in the presence of millimolar concentrations of calcium (33-35). These

89 observations led to the proposal of the "sorting by aggregation" or "sorting for entry" hypothesis

90 in which aggregated granins and associated proteins exclude other soluble proteins in the TGN

91 and promote SG biosynthesis (27, 36-38). However, the relevance of these observations in living

92 cells is yet to be determined as the $\mathrm{pH}$ and calcium concentrations used in these studies are

93 significantly beyond the physiological range $(39,40)$.

94 Liquid-liquid phase separation (LLPS) is increasingly recognized as a major principle of 95 macromolecular organization within membrane-less compartments that enriches certain 96 components and promotes specific biochemical reactions (41-43). The molecules that drive 97 phase separation are referred to as scaffolds, whereas molecules that preferentially partition into 98 the scaffolds are termed clients (44-47). The formation of these condensates is typically driven 99 by multivalent interactions among proteins. One commonly identified element associated with 100 phase separation in proteins is the intrinsically disordered region (IDR), an amino acid sequence 101 characterized by low sequence complexity $(48,49)$. Simple charge patterns and the overall 102 sequence composition of the IDRs are critical for phase separation. Other crucial factors 103 controlling LLPS are the concentration and identity of macromolecules as well as the conditions 
bioRxiv preprint doi: https://doi.org/10.1101/2021.12 22 472607; this version posted December 23,2021 . The copyright holder for this preprint

(which was not certified by peer review) is the author/funder, who has granted bioRxiv a license to display the preprint in perpetuity. It is made available under aCC-BY-NC-ND 4.0 International license.

104 of the microenvironment surrounding the condensates. Environmental conditions that influence

105 the LLPS of soluble proteins include temperature, salt type and concentration, co-solutes, $\mathrm{pH}$, 106 and the volume excluded by others (50).

107 Here, we aimed to gain a comprehensive understanding of the mechanism underlying proinsulin 108 sorting from the Golgi apparatus to ISGs of pancreatic $\beta$-cells as it remains an unresolved 109 question in cell biology. 


\section{Results}

111 This study aimed to gain a comprehensive insight on mechanisms of proinsulin sorting at the

112 TGN. We first analyzed insulin localization in a cell culture model of pancreatic $\beta$-cells (INS1

113 832/13) and observed insulin in punctate structures at the Golgi apparatus (Figure 1A). To confirm

114 this result, we performed pulse-chase experiments with live cells expressing SNAP-tagged

115 proinsulin (29) and monitored de novo synthesized proinsulin at the Golgi apparatus (Fig. 1B).

116 SNAP-tagged proteins were observed in fluorescent structures similar to those observed by

117 immunofluorescence microscopy (Fig. 1C). To determine whether these structures are located

118 outside or inside the TGN, we reconstructed the volume of the TGN using 3D-rendering of

119 confocal stacks from cells labeled using TGN38 and pan-insulin antibodies. Within the volume

120 mask, punctate dots of insulin were observed, implying their presence in the TGN lumen (Figure

121 1D). We further confirmed the presence of electron-dense structures within the Golgi stack via

122 transmission EM of mouse islets (Figure 1E). Proinsulin processing occurs during granule

123 maturation (51), and processing enzymes must be co-sorted into vesicles targeting ISGs to

124 facilitate proper insulin maturation. To test whether proteolytic enzymes colocalize with proinsulin

125 puncta, we labeled the cells with pan-insulin and protein convertase 2 (PC2) antibodies; PC2 was

126 found colocalized with the proinsulin puncta at the Golgi apparatus (Figure 1F).

127 Incubation of cells with Brefeldin A (BFA) has been shown to result in disassembly of the Golgi

128 apparatus and translocation of the associated proteins to the ER (52). Treatment of INS1 832/13

129 cells with BFA for resulted a dramatic change in the staining pattern of TGN38 (Supp Figure 1A),

130 indicating disassembly of the TGN. Importantly, this was accompanied by disappearance of the

131 perinuclear PC2 puncta implying these structures are associated with the Golgi apparatus. If the

132 proinsulin/PC2 puncta are post-Golgi vesicles, they should remain in the perinuclear regions upon

133 treatment with nocodazole, which generates Golgi ministacks (53). However, we found that PC2 
134 was dispersed with the Golgi marker GM130 (Supp figure 1B), further suggesting the association

135 with the Golgi apparatus.

136 Next, we investigated the dynamic nature of proinsulin puncta in the TGN. INS1 832/13 cells were

137 transfected with RINS1, a dual fluorescently tagged form of proinsulin where mCherry is inserted

138 within the C-peptide and super-folder GFP (sfGFP) is present at the C-terminus (54), and

139 monitored using time-lapse live-cell imaging. The proinsulin puncta in the Golgi apparatus were

140 highly dynamic and displayed fission and fusion events (Figure 1G). Overall, the observations

141 reveal that proinsulin is organized in dynamic punctate structures at the Golgi apparatus.

\section{CGB and CGA undergo LLPS in vitro}

144 Although the structure and dynamics of insulin puncta in the TGN displayed properties associated

145 with liquid-like condensates, the polypeptide sequence of proinsulin did not show characteristics

146 associated with proteins undergoing LLPS. Previous work has shown that CGs are significant

147 regulators of proinsulin trafficking and that their depletion impairs insulin granule biosynthesis and

148 glucose-stimulated insulin secretion (29). Analysis of the CGA or CGB sequences using the

149 database PONDR (http://www.pondr.com) or AlphaFold (https://alphafold.ebi.ac.uk), respectively

150 predicted that $50 \%$ of CGB and $90 \%$ of CGA are disordered (Figure 2A). We thus tested whether

151 purified CGs form liquid-like condensates. To purify CGs, we generated CGA and CGB proteins

152 containing sfGFP and His tags at their C-termini (using sfGFP with a monomerizing mutation;

153 Supp figure 2A). Secreted proteins were purified from the culture medium of HEK293 cells stably

154 expressing tagged proteins using Ni-NTA columns; proteins were obtained with high yields and

155 purity (Figure 2C, D). To determine whether CGs form condensates, we changed the buffer from

$156 \mathrm{pH} 7.4$ to 6.1 to match the TGN lumen $\mathrm{pH}(39)$, and the protein solution was plated onto an

157 imaging dish prior to analysis by fluorescence microscopy. We observed CGB

158 condensates/droplets, whereas GFP remained soluble (Figure 2B, C). In contrast to CGB, purified 
CGA-GFP in solution did not form condensates when equilibrated at $\mathrm{pH}$ 6.1. However, condensate formation of CGA was induced by adding PEG 8000 to the protein solution (Figure

161 2D). Upon decreasing the protein concentration, the condensate sizes also decreased (Figure 162 2D).

163 Live-cell imaging of CGB-GFP droplets to determine whether they exhibit liquid-like properties

164 showed that two or more condensates in proximity display fusion and relaxation to a spherical 165 shape (Figure 2E). Moreover, when a small region within the CGB condensate was 166 photobleached, more than $50 \%$ of the fluorescence recovered within one minute, indicating high 167 mobility of proteins within the condensates (Figure 2F, G). CGA condensates induced with PEG 1688000 displayed similar liquid-like behavior (Supp figure 2B, C). These data demonstrate that 169 purified CGs undergo LLPS in vitro and that CGB has a higher potential for phase separation than does CGA.

171

\section{The TGN pH drives CG LLPS while divalent cations are dispensable}

173 Secretory proteins are exposed to changes in the chemical environment as they travel through 174 the sub-compartments (milieu) of the biosynthetic pathway. Having established a straightforward 175 microscopy-based in vitro assay to monitor CG condensation, we investigated the impact of $\mathrm{pH}$ 176 on this process by using the intrinsic $\mathrm{pH}$ difference between the ER and TGN compartments. We 177 analyzed droplet formation by fluorescence microscopy using purified GFP-tagged CGs with 178 buffer conditions of pH 7.3 (ER milieu) or 6.1 (TGN milieu) (39). Interestingly, CGA (with crowding 179 reagent) and $\mathrm{CGB}$ formed droplets at $\mathrm{pH} 6.1$ but not 7.3. This demonstrates that $\mathrm{CG}$ condensates 180 are formed at a $\mathrm{pH}$ consistent with the TGN milieu, suggesting a physiological triggering 181 mechanism for CG condensation.

182 Given that CGs aggregate in the presence of high calcium concentrations (34-36), we tested the 183 influence of calcium on LLPS by incubating GFP-tagged recombinant proteins at $\mathrm{pH} 6.1$ with 
184 varying concentrations of calcium and analyzing droplet formation. CGB-GFP $(10 \mu \mathrm{M})$ solution,

185 centrifuged to pre-clear existing droplets, was diluted to $2.5 \mu \mathrm{M}$ in the presence of varying 186 concentrations of calcium. The steady-state calcium concentration in the TGN is estimated to be $187130 \mu \mathrm{M}$ (40); surprisingly, we did not observe droplet formation for either CGA or CGB at $250 \mu \mathrm{M}$ 188 calcium (Supp figure 3A, C), which is closer to the physiological concentrations in the TGN than 189 are the millimolar-range concentrations used in previous studies. Instead, calcium (5 mM) induced 190 the formation of CGB condensates, which was significantly potentiated at $20 \mathrm{mM}$ calcium based 191 on the size and density of droplets (Figure 3B; Supp Figure 3A, B). Although CGB binds to calcium 192 (55); no structural binding motif, such as an EF-hand domain, has been identified. Consequently, 193 we questioned whether such condensation under high calcium concentrations is specific or can 194 be induced by other divalent cations. Magnesium and manganese at $20 \mathrm{mM}$ induced LLPS of 195 CGB (Figure 3B). However, at $5 \mathrm{mM}$, magnesium failed to enhance CGB LLPS, whereas manganese induced an increase in CGB condensate size (Supp figure 3B). Since CGA does not 197 form condensates on its own in solution, we added calcium to determine if it results in LLPS of 198 CGA without crowding agents. However, even at high concentrations (40 mM), we did not detect 199 CGA droplet formation at pH 6.1 (Supp Figure 3C).

200 Zinc is essential for hexamerization of mature insulin (56) and is present at high concentrations 201 (mM level) in SGs due to the localization of zinc transporters $(21,57,58)$. To test its impact on 202 droplet formation, fluorescent proteins were incubated with high concentrations of zinc $(20 \mathrm{mM})$, 203 after which we observed filamentous aggregates of CGB (Figure 3B). Partial fluorescence 204 recovery after photobleaching (FRAP)—bleaching a small region in the zinc-induced aggregates 205 or calcium-induced condensates to monitor fluorescence recovery within the bleached spot—was 206 used to confirm whether they are indeed insoluble solid aggregates. While calcium-induced 207 condensates recovered fluorescence in the bleached region by more than $50 \%$ within a minute, 208 there was almost no recovery of photobleached zinc aggregates (Figure 3D, E). To further 209 investigate the effects of zinc on CGB, the zinc concentration was titrated. We observed a mixture 
210 of aggregates and condensates at $1 \mathrm{mM}$ zinc and droplets below $1 \mathrm{mM}$ zinc (Figure 3C). In

211 pancreatic $\beta$-cells, as the immature SGs mature, there is a further drop in their luminal $\mathrm{pH}$ to

212 approximately 5.2 (39), which is more acidic than that of the TGN lumen. At pH 5.2, CGB

213 continued to form condensates; however, if the pre-formed condensates were treated with $20 \mathrm{mM}$

214 zinc, an immediate hardening of the condensates accompanied by massive volume shrinkage

215 occurred (Figure 3F). FRAP measurements confirmed differences in condensate fluidity before

216 and after the addition of zinc (Figure 3G, H).

217 The above data reveal that an acidic $\mathrm{pH}$ of 6.1 is the primary driver for CG LLPS and that the

218 presence of divalent cations modulates the LLPS of CGB, contradicting the current understanding

219 that calcium is required for inducing CG aggregation in the TGN. Calcium and other divalent

220 cations can boost the inherent ability of CGB to undergo LLPS, but they are not necessary for the

221 reaction.

222 Proinsulin and CGB are co-sorted into TGN-derived transport carriers

223 Based on the CGB condensation results we hypothesized that it is a necessary step for the sorting

224 of proinsulin at the TGN. Depletion of CGB in INS1 832/13 cells results in impaired proinsulin

225 export from the TGN (29). A similar result was obtained in islets derived from CGB knockout mice

226 (59). If our hypothesis that CGB condensation sorts proinsulin in the TGN is correct, both proteins

227 should colocalize and bud into the same transport carrier exiting the TGN. To address this, we

228 established a pulse-chase approach to monitor the simultaneous export of proinsulin and CGB

229 from the TGN in living cells. We expressed CLIP-tagged CGB in INS1 832/13 cells stably

230 expressing SNAP-tagged proinsulin (Figure 4A). Newly synthesized SNAP-proinsulin and CLIP-

231 CGB entering the TGN were labeled with their respective fluorescent analogs $(t=0)$ and observed

232 to colocalize (Fig. 4A). Following a 2-hour chase of the respective fluorescent SNAP or CLIP

233 probes, both proteins colocalized in cytoplasmic granules, indicating that they are sorted into the

234 same transport carriers exiting the TGN (Figure 4A). Following a 2-hour chase of the respective

235 fluorescent SNAP or CLIP probes, both proteins colocalized in cytoplasmic granules, indicating 
236 they were sorted into the same transport carriers exiting the TGN (Figure 4A). Moreover,

237 proinsulin at steady-state showed colocalization with CGB, CGA, and secretogranin III in the TGN,

238 TGN-derived vesicles, and cytoplasmic granules (Figure 4B-D).

239 To gain further insights into the relationship between proinsulin and CGB, we applied our well-

240 established in vitro system mimicking TGN conditions. CGB-GFP (2.5 $\mu$ M final concentration $)$ and

241 mCherry-tagged proinsulin (1 $\mu \mathrm{M}$ final concentration) were combined at $\mathrm{pH} 6.1$ and 3\% PEG 8000

242 was used to induce robust CGB condensate formation. Recruitment of proinsulin to the CGB

243 condensates was readily observed (Figure 4F); no co-condensation of GFP and proinsulin

244 occurred (Figure 4F). Based on these findings and previously published results, we propose that

245 CGs co-condense in the luminal milieu of the TGN. Moreover, CGB condensation results in

246 proinsulin co-segregation and export from the TGN.

248 Ectopic expression of constitutively secreted proteins results in their targeting to SGs and co-secretion with insulin

250 Our findings so far suggest that CG condensates containing proinsulin and processing enzymes

251 bud out vesicles from the TGN to form immature secretory granules, which in turn mature into

252 fully functional insulin granules. By necessity, molecules destined for lysosomes or constitutively

253 secreted proteins would be segregated from the CG condensates in the TGN. To monitor the co-

254 segregation or segregation of cargo molecules within the TGN lumen, we examined a subset of

255 proteins destined for locations other than SGs. Significant colocalization of proinsulin and

256 carboxypeptidase E, an SG cargo and proinsulin processing enzyme, was observed (Figure 5A,

257 D). On the other hand, comparison of the localization of proinsulin and the cargo receptors of

258 lysosomal hydrolases (M6PR or IGF2R) revealed that these proteins segregate within the TGN

259 lumen (Figure 5B, C and Figure 5E, F). Similarly, endogenous cathepsin B was segregated from 
260 proinsulin in the TGN (Supp figure 4B). This suggests that lysosomal hydrolases and their

261 receptors exit from different regions of the TGN.

262 Next, we wondered whether constitutively secreted proteins segregate from proinsulin CGA 263 droplets, which would align with the "sorting for entry" model (38). Cab45 sorts a subset of 264 proteins, including LyzC, to the cell surface in HeLa cells (60). Therefore, proinsulin localization 265 was compared with that of ectopically expressed LyzC or EqSOL, a soluble bulk flow marker.

266 Unexpectedly, we observed colocalization of these proteins with proinsulin, and both LyzC and

267 EqSOL were transported to SGs in insulin-secreting cells (Figure 5G, H). We then analyzed 268 localization of the ectopically expressed lysosomal hydrolase cathepsin D (CatD) in INS1 832/13 269 cells. In contrast to the endogenous hydrolase, ectopically expressed CatD-sfGFP was not 270 targeted to the lysosome but instead routed to insulin granules (Figure 5I). However, this effect 271 appears to be limited to soluble TGN cargoes, as ectopic expression of HA-tagged SPCA1, a 272 transmembrane protein localized to the TGN, did not result in SPCA1 and proinsulin colocalization 273 but instead remained TGN localized (Figure 5J). To further investigate whether routing to SGs 274 depends on CGs, we expressed mCherry-tagged LyzC and CGA-sfGFP in HeLa cells, which are 275 naturally deficient in CGs and SGs. We detected ectopic secretory granules in HeLa cells 276 expressing CGA-sfGFP and observed the routing of LyzC-mCherry to these granules (Figure 5K).

277 These data indicate that CG condensates can non-specifically recruit client proteins and that CG 278 expression overrides existing pathways for sorting soluble proteins to favor SG accumulation.

279 Since overexpression of secreted soluble proteins leads to their routing to the SGs in INS1 832/13 280 cells, we assessed whether they are also secreted in response to stimulus, as is the case with 281 insulin (61). Indeed, at basal levels (3 $\mathrm{mM}$ glucose), we observed a minimal amount of basal 282 secretion in cells expressing the constitutively secreted protein LyzC-GFP and SNAP-tagged C283 peptide (proxy for insulin secretion). However, upon glucose (15 mM) and potassium chloride (35 $284 \mathrm{mM}$ ) stimulation of INS1 832/13 cells, both LyzC-GFP and insulin were co-secreted (Figure 5L). 
285 These results suggest that CG condensates recruit soluble proteins by nonspecific mechanisms

286 that do not rely on the sequence or structural motif of the client. The co-condensation of soluble

287 proteins with CGs results in their routing to SGs, which in turn allows them to be co-secreted with

288 insulin in response to glucose stimulation.

\section{LyzC gets recruited to granin condensates in vitro}

291 We then determined whether other soluble proteins such as LyzC and CatD are recruited to CGB 292 condensates in vitro and whether the liquid-like droplets or aggregates of CGB are equally 293 competent to recruit cargo. CGB and Cy3-tagged LyzC were combined at 2.5:1 molar ratios and 294 droplet formation was induced using calcium. Under these conditions, Cy3-LyzC was recruited to 295 the CGB condensates (Figure 6A, B). Since we observed CGB aggregates only in the presence 296 of zinc, we tested whether zinc-induced CGB aggregates recruit Cy3-LyzC. In contrast to the 297 current view that aggregated CGs recruit clients, we did not detect Cy3-LyzC recruitment into the 298 zinc-containing CGB aggregates (Figure 6A, B). In a similar experiment, we confirmed that Cy3299 tagged CatD was also recruited to the CGB condensate, supporting a client recruitment mechanism that is independent of a specific sequence (Figure 6E).

301 Next, we investigated how CG condensates select cargo molecules. LyzC is a small protein (14 $302 \mathrm{kDa}$ ) and the molecular weight of CatD is approximately $45 \mathrm{kDa}$. We thus assessed whether the 303 small size of the protein allows entry into the CGB condensates by comparing Cy3-LyzC and Cy3304 labeled rabbit IgG (MW $150 \mathrm{kDa}$ ) recruitment. Based on the intensity profile, LyzC filled the 305 complete volume of the CGB condensate, whereas IgG only populated the edges of the CGB 306 condensates, with little signal detected in the center of the droplet (Figure 6C, D). This suggests 307 that CGB condensates enrich smaller molecules and exclude those that have a high molecular 308 weight. 
These results suggest that while CGB aggregates cannot recruit cargo and must be in a liquidlike state to do so, CGB condensates can recruit small sized clients independent of any sequence

311 or structural features.

313 Truncation of CGB impacts phase separation potential and the ability to generate ectopic

\section{4 granules}

315 While we have just begun to understand the molecular mechanisms governing LLPS, there is no 316 general defining factor that drives LLPS. To narrow down the region in CGB driving LLPS, we

317 truncated the CGB protein into distinct parts based on its predicted structure (PONDR database);

318 the N-terminal domain of CGB (amino acids: 46-334 aa) is highly unstructured (high degree of 319 disorder) compared with the C-terminal (amino acids: 335-667; Figure 7A). Hence, sfGFP- or 320 mCherry-tagged truncation mutants of CGB, CGB_N term-GFP and CGB_C term-mCherry, were 321 generated. For each mutant, the signal sequence of CGB was incorporated at the $\mathrm{N}$-terminus to 322 allow transit through the secretory pathway. Neither of the truncation mutants displayed LLPS at $323 \mathrm{pH} 6.1$ (Supp figure 5A); however, upon addition of 3\% PEG 8000, the N-terminal was observed

324 to undergo a significantly more potent LLPS than that of the C-terminal (Figure 7B). There was a 325 difference in area covered by the droplets observed for each mutant, with the effects being much 326 stronger for the CGB C-terminal fusion protein. (Figure 7C, E). The inability of the CGB C-terminal 327 to undergo LLPS was not due to the mCherry tag because the sf-GFP-tagged version displayed 328 the same phenotype (Supp figure 5B). Interestingly, when the $\mathrm{N}$ - and C-terminal truncation 329 mutants were combined and phase separation was induced in the presence of $3 \%$ PEG 8000 , 330 the mixture displayed phase separation comparable to that of full-length CGB-GFP (Figure 7D, 331 E). These results suggest that while most of the information responsible for mediating LLPS of 332 CGB is encoded by the N-terminal domain, the C-terminal is required for optimal function. 
333 To determine the contributions of LLPS to SG biogenesis, we took advantage of the CG protein

334 characteristic of inducing ectopic granule-like structures when expressed in non-secretory cells

$335(30,62)$. For this purpose, we used stable HEK293 cell lines expressing CGB-GFP, CGB_N term-

336 GFP, and CGB_C term-GFP and induced expression using doxycycline. We observed that

337 ectopic expression of both full-length and N-terminal CGB induced biogenesis of ectopic granules,

338 whereas the C-terminal CGB did not (Figure 7F, G). Altogether, these results reveal that the

339 potential of CGB to undergo LLPS is directly linked to its ability to induce SG formation. Thus, CG

340 LLPS is not only critical for sorting soluble proteins within the TGN lumen but also for driving SG

341 biogenesis.

343 Electrostatic interactions mediate LLPS of CGB

344 Electrostatic interactions have been shown to drive LLPS (63). In the case of the protein Ddx4,

345 the arrangement of its amino acids into clusters of similarly charged residues has been shown to 346 drive LLPS (64). While CGB is rich in acidic amino acid residues, a striking feature in the CGB

347 protein are five clusters of negatively charged amino acids (Figure 8A). There are also dibasic

348 sites that have also been shown to be proteolytic cleavage sites, with most present within the C-

349 terminus. Based on these features, we hypothesized that electrostatic interactions drive the LLPS

350 of CGB.

351 The role of electrostatic interactions in mediating LLPS can be determined by testing the ability of

352 proteins to form condensates at different salt concentrations. At high salt concentrations, protein-

353 salt interactions dominate protein-protein interactions, thus inhibiting LLPS. Accordingly, when

354 CGB was equilibrated at $\mathrm{pH} 6.1$ in the presence of $500 \mathrm{mM} \mathrm{NaCl}$ (high salt), we did not observe

355 condensate formation (Figure 8B), indicating that charge-charge interactions drive LLPS of CGB.

356 To probe this further, all acidic residues in the five stretches were mutated to alanine

357 (CGB_5(ED)/A) and their ability to undergo LLPS was monitored. CGB_5(ED)/A_GFP formed 
358 condensates in the absence of crowding agents, similar to the WT (Figure 8C). Since CGB does

359 not have a well-defined calcium binding domain, we reasoned that these stretches are potential

360 calcium-binding sites and tested whether CGB_5(ED)/A_GFP undergoes LLPS in the presence

361 of calcium. Interestingly, condensate formation was not observed in the presence of $20 \mathrm{mM}$

362 calcium, which otherwise induced robust LLPS of WT CGB (Figure 8D). These findings suggest

363 that CGB LLPS is driven by electrostatic interactions and that the five stretches of acidic amino

364 acids potentiate this reaction by binding to calcium. 


\section{Discussion}

367 To investigate the molecular role of CGs in proinsulin sorting, we purified fully functional 368 recombinant $\mathrm{CGA}$ and $\mathrm{CGB}$, which are significant drivers of granule biosynthesis, from 369 mammalian cells. In combination with cell biology-based approaches, we describe a model for 370 protein sorting towards SGs. We demonstrated that CGs undergo LLPS in conditions resembling 371 the TGN milieu to form a client scaffold. The $\mathrm{pH}$ in the TGN lumen is the primary driver of CG 372 condensation and client (proinsulin) recruitment, whereas calcium is dispensable for the reaction.

373 Our experiments revealed that phase separated CGs act as a "client sponge," incorporating 374 clients based on their size. Finally, we demonstrated that LLPS is crucial for client recruitment.

375 Solid aggregates of CGB fail to recruit soluble clients, and truncation of CGB, which significantly 376 affects its capacity to undergo LLPS, impairs the formation of ectopic SG-like structures in non-

377 secretory cells. These results are in contrast to the pre-existing dogma of cargo segregation 378 between constitutive and regulated pathways $(21,23,38)$

\section{LLPS drives cargo condensation in the TGN}

The predominant model that explains cargo sorting at the TGN in specialized secretory cells is

381 termed "sorting for entry" or "sorting by aggregation" (38), and has two main tenets: (i) granin 382 family proteins undergo aggregation at an acidic $\mathrm{pH}$ and in the presence of calcium, after which 383 the resultant aggregate, surrounded by a membrane, buds off from the TGN to form the immature

384 SG and (ii) granins aggregate and exclude proteins destined for lysosomes or constitutively 385 secreted proteins, mediating cargo sorting towards the SG at the TGN. These conclusions were 386 derived from experiments using isolated granule contents from adrenal or pituitary glands and 387 purified CGA or CGB from vesicle lysates of bovine adrenal medullary chromaffin cells (30, 35 , 388 36). Aggregation was monitored by either testing the abundance of natural soluble CGs in pellet 389 fractions upon centrifugation or by changes in turbidity upon inducing aggregation at $\mathrm{pH} 5.5$ and 390 in the presence of high millimolar calcium concentrations. While informative, these studies utilized 
391 conditions that are not representative of the natural TGN environment, and thus have limited

392 relevance in understanding how CG-dependent sorting at the TGN occurs in a physiological

393 setting. Moreover, the molecular mechanism underlying the aggregation process as well as

394 specific cargo sorting by the aggregate remain unclear. Our results show that it is the liquid-like

395 state that is essential for cargo recruitment as the CGB aggregate fails to recruit client molecules.

396 Thus, LLPS of CGs results in the formation of a scaffold within the TGN lumen that recruits soluble

397 clients like proinsulin for their subsequent delivery to the SGs.

398 In CG-LLPS, pH is the main driver while calcium is dispensable

399 In endocrine cells, the sorting process has been shown to strictly depend on the acidification of 400 intracellular compartments because the addition of acidotropic drugs diverts regulated secretory 401 proteins to the constitutive pathway, completely suppressing the formation of new secretory 402 granules (23). CGs are synthesized in the ER and transported to the Golgi apparatus, where they 403 are sorted and targeted to the SGs. Since LLPS of CGs facilitates cargo sorting towards the SGs, 404 CGs must be in soluble form within the ER lumen and undergo LLPS at the TGN.

405 As proteins move along the secretory pathway, there is a $\mathrm{pH}$ gradient from an almost neutral $\mathrm{pH}$ 406 (7.3) in the ER lumen that progressively becomes acidic from the cis- to the trans-Golgi, with a 407 TGN pH of around 6.1 (65-68). Our results demonstrate that $\mathrm{pH}(6.1)$, resembling the TGN milieu 408 is a critical driver of LLPS, whereas calcium is not necessary; this contrasts with previous studies 409 that have indicated calcium is required for the aggregation of CGs. These results are further 410 strengthened by our findings on the behavior of the CGB_5(ED)/A mutant protein, which 411 underwent LLPS on its own at high protein concentrations but failed to do so at low protein 412 concentrations in the presence of calcium. Notably, these results also highlight the five acidic 413 stretches in CGB as potential calcium binding sites.

414 Similarly, LLPS of CGA in the presence of crowding agents was favored at $\mathrm{pH} 6.1$, and no 415 aggregation of CGA was observed in the presence of $40 \mathrm{mM}$ calcium. These results further 
416 emphasize that acidic $\mathrm{pH}$ and not calcium is the most critical parameter governing the LLPS of

417 CGs. It is not surprising considering that calcium concentrations in the ER $(400 \mu \mathrm{M} ;(40))$ are

418 considerably higher than those at the TGN. We assume that protonation of some of negatively

419 charged amino acid residues of CGA (PI 4.58) or CGB (PI 5.03) at low pH conditions can promote

420 LLPS by reducing electrostatic repulsion; consequently, the acidic milieu could induce the

421 condensation of CGs in the TGN.

\section{Differential effects of divalent cations on LLPS and aggregation of CGB}

423 While calcium is not essential for LLPS of CGB, at concentrations above $5 \mathrm{mM}$, it boosts its ability

424 to undergo LLPS. However, our results show that the effect is not limited to calcium as

425 magnesium, manganese, and zinc can also induce LLPS. Manganese, which is highly abundant

426 in the TGN, shows a higher potential than calcium for inducing LLPS based on the size and area

427 covered by the droplets. The requirement of CGB to be present in a liquid-like scaffold within the

428 TGN lumen is further emphasized based on the differences in cargo recruitment to condensates

429 versus aggregates. LyzC, sorted to SG in INS1 832/13 cells and co-condensed with CBG in

430 calcium-induced droplets, fails to be recruited to zinc-induced CGB aggregates. High zinc

431 concentrations only occur in the SGs because of the localization of zinc transporters to the SGs

$432(22,57)$. Based on the differential effects of divalent cations on CGB and their location in the

433 secretory pathway, we suggest that CGB undergoes a transition from a liquid-like condensate to

434 an aggregate as it moves along the secretory pathway from the TGN to the SGs, and zinc-

435 dependent aggregation may be required for client release within the SG. Interestingly, a recent

436 preprint from the Hagen laboratory has demonstrated cargo segregation within secretory granules

437 from the fly salivary gland in a calcium- and $\mathrm{pH}$-dependent fashion that also relies on glycosylation

438 (69). It remains possible that zinc plays an equivalent role in mammalian secretory cells. 


\section{1 receptor-independent sorting}

442 According to the second tenet of the "sorting for entry" model, aggregation of CGs is thought to

443 be a driving force at the TGN to mediate cargo sorting. Cargo molecules destined for SGs, such

444 as proinsulin, neuropeptide $\mathrm{Y}$ (NPY), and processing enzymes PC1/3, PC2, and CPE, would be

445 brought into the aggregate. In contrast, lysosomal hydrolases and other constitutive cargo

446 molecules would be segregated from the aggregate, thus facilitating sorting. It remains unclear

447 how molecules such as proinsulin are brought into the aggregate when there is no known receptor

448 for this process and whether there is a specific sorting mechanism.

449 Our results challenge the specific sorting aspect of the "sorting by entry" model, as we show that 450 ectopic expression of soluble proteins, such as LyzC-GFP or EqSOL-GFP, in INS1 832/13 cells

451 are secreted constitutively in HeLa cells, resulting in their targeting to SGs. Interestingly, 452 overexpression of CatD, a lysosomal hydrolase, also showed the same phenotype. Thus, we 453 propose that phase-separated granin proteins form scaffolds that act like a sponge that brings 454 soluble proteins together into the condensed phase. Secretion of LyzC-GFP in response to 455 glucose stimulation in INS1 832/13 cells suggests that LyzC and insulin remain in SGs and are 456 released together in response to glucose stimulation. These findings contradict the "sorting by 457 retention" model (70) which proposes that non-secretory proteins are removed by vesicles that 458 bud off from the SG, thus mediating differential sorting of regulated versus constitutively secreted 459 cargo.

460 Given our data showing co-segregation of proinsulin, M6PR, and IGF2R within the TGN volume 461 and routing of lysosomal hydrolases to SGs upon overexpression, we suggest that at endogenous 462 levels, lysosomal hydrolases are trafficked to lysosomes in a cargo receptor-dependent manner. 463 Upon overexpression, the receptors are likely to be saturated, and the hydrolases become clients 464 of the CG scaffold. The expression of granin proteins drives the targeting of soluble proteins to 
465 SGs as the dominant pathway. In parallel, the significance of CGs in targeting clients to SGs is

466 highlighted by the fact that expression of CGA reroutes LyzC to ectopic SGs. This is in line with

467 previous findings showing that expression of Xenopus laevis CGA proteins in Cos7 cells directs

468 co-expressed NPY to the ectopic CGA-derived granules (71). NPY, however, is targeted to SGs

469 in specialized cells. Our results expand on this idea and show that CGA expression indeed

470 reorganizes TGN sorting, as it can reroute LyzC to SGs, which is otherwise secreted constitutively

471 from HeLa cells.

472 The nonspecific recruitment of clients to cells was in agreement with our in vitro assay findings.

473 CGB scaffolds recruited LyzC, CatD, and a small positively charged polypeptide. However, it is

474 interesting that large molecules such as $\lg$ G remain attached to the rims of CGB scaffolds and do

475 not effectively enter the condensates, thus indicating a likely size-based cut-off for recruitment.

476 Failure of IgG to co-precipitate along with granin aggregates in a previous study was used to

477 define segregation of constitutive and regulated secretory cargoes, which formed the basis of

478 sorting by aggregation (72). Our results refute the clear segregation of cargoes at the TGN based

479 on either specific sequence or structural elements in the client proteins or their destination, and

480 instead highlight that the larger size of $\operatorname{lgG}$ is what prevents it from being co-sorted to the SGs.

481 SGs are not limited to pancreatic $\beta$-cells but are also present in the $\alpha$ cells of the pancreas, which

482 secrete glucagon. We propose that instead of having unique receptors for different cargo

483 molecules in these different cell types, cells utilize an LLPS sorting mechanism wherein cargo

484 molecules are recruited to the granin sponge by their abundance within the TGN lumen, resulting

485 in their targeting to SGs. Supporting this, the expression of GFP fused to a signal sequence

486 directing it into the secretory pathway leads to its targeting to SGs in AtT-20 and PC-12 cells (73).

487 Since molecules like insulin or NPY are crucial for physiology and metabolism, specialized cells

488 like pancreatic $\beta$-cells express different members of the granin family, including CGA, CGB,

489 SCG2, VGF. Our studies have demonstrated that both CGA and CGB can undergo LLPS, 
490 although with a difference in capacity, and in silico analysis of VGF also showed disordered

491 regions within the proteins that may be indicative of LLPS. The capability of VGF to undergo LLPS

492 needs to be tested, as ectopic expression of VGF also induces ectopic granule-like structures in

493 NIH3T3 cells (74). Along similar lines, Spiess and colleagues showed that peptide hormone

494 precursors including pro-vasopressin, pro-oxytocin, and POMC can form SGs in cell lines that

495 normally lack regulated secretion (62). POMC, for instance, contains a highly disordered region,

496 and it can be speculated that it forms similar scaffolds in the TGN that promote sorting of SG-

497 targeted proteins. This suggests that the abundance of a phase separated scaffold protein in the

498 TGN may regulate SG biosynthesis, which must be tested in future experiments.

499 Although client recruitment to condensates of synapsin or ZO1 seems to be specific, mediated

500 by physical interactions between the scaffolds and the clients $(75,76)$, LLPS driven by IDRs of

501 FUS, hnRNP A1, and elF4GIl has been shown to recruit globular proteins to the condensates,

502 presumably due to interaction with the IDR (77). We believe that such a mechanism, in

503 combination with the size-based cut off, determines the composition of granin condensates.

504 While our studies explain how CGB scaffolds recruit clients for sorting to SGs, it remains unclear

505 how the condensate is associated to the membrane for budding of the vesicles from the TGN.

506 Former research has proposed that soluble SCGIII or CPE can act as a tether for CGA aggregates

507 by binding to cholesterol (78). Based on our findings it is conceivable that granin scaffolds also

508 accumulate tethering proteins such as SCGIII, thereby attaching the condensate to cholesterol-

509 rich TGN membranes. Alternatively, phase separation of condensed protein complexes has been

510 proposed to cause membrane budding and fission $(79,80)$. In this context, it was suggested that

511 the assembly of IDPs artificially targeted to a membrane surface induces membrane curvature

512 due to a substantial compressive effect in the membrane plane (80-83). It would indeed be

513 interesting to test whether CG condensates can drive membrane budding using an artificial

514 membrane and if tethering to the membrane occurs by cholesterol binding. 
515 Overall, our findings identify LLPS as an essential cellular process that is responsible for cargo

516 sorting of soluble proteins towards SGs and that failure of LLPS impairs SG biogenesis.

518 Author Contributions

519 Conceptualization: AP, JVB

520 Methodology: AP, MT, YZ, SBS, JVB

521 Investigation: AP, MT, CKB, SCB, KER, JZ, BRR,

522 Visualization: AP, MT, CKB, SCB, KER, JZ, BRR,

523 Funding acquisition: JVB

524 Project administration: AP, JZ, SBS, JVB

525 Supervision: YZ, SBS, JVB

526 Writing - original draft: AP, JVB

527 Writing - review \& editing: AP, MT, CKB, SCB, KER, JZ, BRR, YZ, SBS, JVB 


\section{Bibliography}

538 1. M. Uhlén, M. J. Karlsson, A. Hober, A.-S. Svensson, J. Scheffel, D. Kotol, W. Zhong, A. 539 Tebani, L. Strandberg, F. Edfors, E. Sjöstedt, J. Mulder, A. Mardinoglu, A. Berling, S. 540 Ekblad, M. Dannemeyer, S. Kanje, J. Rockberg, M. Lundqvist, M. Malm, A.-L. Volk, P. 541 Nilsson, A. Månberg, T. Dodig-Crnkovic, E. Pin, M. Zwahlen, P. Oksvold, K. von Feilitzen, 542 R. S. Häussler, M.-G. Hong, C. Lindskog, F. Ponten, B. Katona, J. Vuu, E. Lindström, J. Nielsen, J. Robinson, B. Ayoglu, D. Mahdessian, D. Sullivan, P. Thul, F. Danielsson, C.

547 2. C. Frantz, K. M. Stewart, V. M. Weaver, The extracellular matrix at a glance. J. Cell Sci. $548 \quad$ 123, 4195-4200 (2010).

549 3. G. Blobel, INTRACELLULAR PROTEIN TOPOGENESIS. Biochem. Soc. Trans. 9, 85P$550 \quad$ 85P (1981).

551 4. J. Dancourt, C. Barlowe, Protein sorting receptors in the early secretory pathway. Annu. Rev. Biochem. 79, 777-802 (2010).

553 5. S. R. Pfeffer, J. E. Rothman, Biosynthetic protein transport and sorting by the endoplasmic reticulum and Golgi. Annu. Rev. Biochem. 56, 829-52 (1987).

555 6. S. Emr, B. S. Glick, A. D. Linstedt, J. Lippincott-Schwartz, A. Luini, V. Malhotra, B. J. Marsh, through the Golgi-taking stock in a new era. J. Cell Biol. 187, 449-453 (2009).

558 7. R. W. Klemm, C. S. Ejsing, M. A. Surma, H.-J. Kaiser, M. J. Gerl, J. L. Sampaio, Q. de 
562 8. R. Di Martino, L. Sticco, A. Luini, Regulation of cargo export and sorting at the trans-Golgi 563 network. FEBS Lett. 593, 2306-2318 (2019).

564 9. D. Stalder, D. C. Gershlick, Direct trafficking pathways from the Golgi apparatus to the 565 plasma membrane. Semin. Cell Dev. Biol. 107, 112-125 (2020).

566 10. M. A. De Matteis, A. Luini, Exiting the Golgi complex. Nat. Rev. Mol. Cell Biol. 9, 273-284 $567 \quad$ (2008).

568 11. B. H. Hummer, D. Maslar, M. Soltero-Gutierrez, N. F. de Leeuw, C. S. Asensio, Differential 569 sorting behavior for soluble and transmembrane cargoes at the trans-Golgi network in 570 endocrine cells. Mol. Biol. Cell. 31, 157-166 (2020).

571 12. R. Lara-Lemus, M. Liu, M. D. Turner, P. Scherer, G. Stenbeck, P. Iyengar, P. Arvan, 572 Lumenal protein sorting to the constitutive secretory pathway of a regulated secretory cell. $573 \quad$ J. Cell Sci. 119, 1833-1842 (2006).

574 13. P. Arvan, B. Zhang, L. Feng, M. Liu, R. Kuliawat, Lumenal protein multimerization in the 575 distal secretory pathway/secretory granules. Curr. Opin. Cell Biol. 14, 448-453 (2002).

576 14. P. Arvan, Secretory Protein Trafficking: Genetic and Biochemical Analysis. Cell Biochem. 577 Biophys. 40, 169-178 (2004).

578 15. M. Liu, Y. Huang, X. Xu, X. Li, M. Alam, A. Arunagiri, L. Haataja, L. Ding, S. Wang, P. Itkin-

16. G. Palade, Intracellular aspects of the process of protein synthesis. Science. 189, 867 (1975).

584 17. L. Orci, M. Ravazzola, A. Perrelet, (Pro)insulin associates with Golgi membranes of pancreatic B cells. Proc. Natl. Acad. Sci. 81, 6743-6746 (1984).

586 18. M. G. FARQUHAR, J. J. REID, L. W. DANIELL, Intracellular Transport and Packaging of 
19. S. A. Tooze, J. C. Stinchcombe, Biogenesis of secretory granules. Semin. Cell Biol. 3, 35766 (1992).

591 20. M. Germanos, A. Gao, M. Taper, B. Yau, M. A. Kebede, Inside the Insulin Secretory $592 \quad$ Granule. Metabolites. 11, 515 (2021).

593 21. J. C. Hutton, The insulin secretory granule. Diabetologia. 32, 271-81 (1989).

594 22. T. J. Nicolson, E. A. Bellomo, N. Wijesekara, M. K. Loder, J. M. Baldwin, A. V. 595 Gyulkhandanyan, V. Koshkin, A. I. Tarasov, R. Carzaniga, K. Kronenberger, T. K. Taneja, 596 G. Da Silva Xavier, S. Libert, P. Froguel, R. Scharfmann, V. Stetsyuk, P. Ravassard, H. 597 Parker, F. M. Gribble, F. Reimann, R. Sladek, S. J. Hughes, P. R. V. Johnson, M. Masseboeuf, R. Burcelin, S. A. Baldwin, M. Liu, R. Lara-Lemus, P. Arvan, F. C. Schuit, M. B. Wheeler, F. Chimienti, G. A. Rutter, Insulin storage and glucose homeostasis in mice null for the granule zinc transporter ZnT8 and studies of the type 2 diabetes-associated variants. Diabetes. 58, 2070-2083 (2009).

23. T. L. Burgess, R. B. Kelly, Constitutive and Regulated Secretion of Proteins. Annu. Rev. Cell Biol. 3, 243-293 (1987).

24. B. Gumbiner, R. B. Kelly, Two distinct intracellular pathways transport secretory and membrane glycoproteins to the surface of pituitary tumor cells. Cell. 28, 51-59 (1982).

25. M. Masini, L. Marselli, M. Bugliani, L. Martino, P. Masiello, P. Marchetti, V. De Tata, Ultrastructural morphometric analysis of insulin secretory granules in human type 2 diabetes. Acta Diabetol. 49, 247-252 (2012).

26. J. F. Habener, M. Amherdt, M. Ravazzola, L. Orci, Parathyroid hormone biosynthesis. Correlation of conversion of biosynthetic precursors with intracellular protein migration as determined by electron microscope autoradiography. J. Cell Biol. 80, 715-31 (1979).

612 27. S. A. Tooze, W. B. Huttner, Cell-free protein sorting to the regulated and constitutive 613 secretory pathways. Cell. 60, 837-47 (1990). 
614 28. T. Kim, J.-H. Tao-Cheng, L. E. Eiden, Y. P. Loh, Chromogranin A, an "On/Off" Switch 615 Controlling Dense-Core Secretory Granule Biogenesis. Cell. 106, 499-509 (2001).

616 29. S. C. Bearrows, C. J. Bauchle, M. Becker, J. M. Haldeman, S. Swaminathan, S. B. 617 Stephens, Chromogranin B regulates early-stage insulin granule trafficking from the Golgi 618 in pancreatic islet $\beta$-cells. J. Cell Sci. 132, jcs231373 (2019).

619 30. Y. H. Huh, S. H. Jeon, S. H. Yoo, Chromogranin B-induced Secretory Granule Biogenesis. 620 J. Biol. Chem. 278, 40581-40589 (2003).

621 31. A. Rustom, M. Bajohrs, C. Kaether, P. Keller, D. Toomre, D. Corbeil, H.-H. Gerdes, 622 Selective delivery of secretory cargo in Golgi-derived carriers of nonepithelial cells. Traffic. $623 \quad 3,279-88(2002)$.

624 32. I. Wacker, C. Kaether, A. Krömer, A. Migala, W. Almers, H. H. Gerdes, Microtubule625 dependent transport of secretory vesicles visualized in real time with a GFP-tagged secretory protein. J. Cell Sci. 110 ( Pt 1, 1453-63 (1997).

33. E. Chanat, A. S. Dittié, S. A. Tooze, in Protein Targeting Protocols (Humana Press, New Jersey, United States, 1998; http://link.springer.com/10.1385/0-89603-487-9:285), vol. 88, pp. 285-324.

34. V. Colomer, G. A. Kicska, M. J. Rindler, Secretory Granule Content Proteins and the Luminal Domains of Granule Membrane Proteins Aggregate in Vitro at Mildly Acidic pH. J. Biol. Chem. 271, 48-55 (1996).

35. S. H. Yoo, $\mathrm{pH}-$ and $\mathrm{Ca} 2+$-induced Conformational Change and Aggregation of Chromogranin B. J. Biol. Chem. 270, 12578-12583 (1995).

36. E. Chanat, W. B. Huttner, Milieu-induced, selective aggregation of regulated secretory

637 37. E. Chanat, S. W. Pimplikar, J. C. Stinchcombe, W. B. Huttner, What the granins tell us about the formation of secretory granules in neuroendocrine cells. Cell Biophys. 19, 85-91 (1991). 
640

641

642

643

644

645

646

647

648

649

650

651

652

653

654

655

656

657

658

659

660

661

662

663

664

665

38. S. A. Tooze, Biogenesis of secretory granules in the trans-Golgi network of neuroendocrine and endocrine cells. Biochim. Biophys. Acta - Mol. Cell Res. 1404, 231-244 (1998).

39. P. Paroutis, N. Touret, S. Grinstein, The $\mathrm{pH}$ of the Secretory Pathway: Measurement, Determinants, and Regulation. Physiology. 19, 207-215 (2004).

40. P. Pizzo, V. Lissandron, P. Capitanio, T. Pozzan, Ca2+ signalling in the Golgi apparatus. Cell Calcium. 50, 184-192 (2011).

41. Y. Shin, C. P. Brangwynne, Liquid phase condensation in cell physiology and disease. Science. 357 (2017), doi:10.1126/science.aaf4382.

42. S. Alberti, A. A. Hyman, Biomolecular condensates at the nexus of cellular stress, protein aggregation disease and ageing. Nat. Rev. Mol. Cell Biol. 22, 196-213 (2021).

43. S. Alberti, The wisdom of crowds: Regulating cell function through condensed states of living matter. J. Cell Sci. 130, 2789-2796 (2017).

44. S. F. Banani, A. M. Rice, W. B. Peeples, Y. Lin, S. Jain, R. Parker, M. K. Rosen, Compositional Control of Phase-Separated Cellular Bodies. Cell. 166, 651-663 (2016).

45. F. Orti, A. M. Navarro, A. Rabinovich, S. J. Wodak, C. Marino-Buslje, Insight into membraneless organelles and their associated proteins: Drivers, Clients and Regulators. Comput. Struct. Biotechnol. J. 19, 3964-3977 (2021).

46. M. Feric, N. Vaidya, T. S. Harmon, D. M. Mitrea, L. Zhu, T. M. Richardson, R. W. Kriwacki, R. V. Pappu, C. P. Brangwynne, Coexisting Liquid Phases Underlie Nucleolar Subcompartments. Cell. 165, 1686-1697 (2016).

47. I. Sanchez-Burgos, J. R. Espinosa, J. A. Joseph, R. Collepardo-Guevara, Valency and Binding Affinity Variations Can Regulate the Multilayered Organization of Protein Condensates with Many Components. Biomolecules. 11, 278 (2021).

48. J. D. Forman-Kay, T. Mittag, From sequence and forces to structure, function, and evolution of intrinsically disordered proteins. Structure. 21, 1492-1499 (2013).

49. E. W. Martin, A. S. Holehouse, Intrinsically disordered protein regions and phase 
separation: sequence determinants of assembly or lack thereof. Emerg. Top. Life Sci. 4, 307-329 (2020).

50. S. Boeynaems, S. Alberti, N. L. Fawzi, T. Mittag, M. Polymenidou, F. Rousseau, J. Schymkowitz, J. Shorter, B. Wolozin, L. Van Den Bosch, P. Tompa, M. Fuxreiter, Protein Phase Separation: A New Phase in Cell Biology. Trends Cell Biol. 28, 420-435 (2018).

51. Z. Fu, E. R. Gilbert, D. Liu, Regulation of Insulin Synthesis and Secretion and Pancreatic Beta-Cell Dysfunction in Diabetes. Curr. Diabetes Rev. 9, 25-53 (2013).

52. J. Alcalde, P. Bonay, A. Roa, S. Vilaro, I. V. Sandoval, Assembly and disassembly of the Golgi complex: Two processes arranged in a cis-trans direction. J. Cell Biol. 116, 69-83 (1992).

53. H. C. Tie, D. Mahajan, B. Chen, L. Cheng, A. M. J. VanDongen, L. Lu, A novel imaging method for quantitative Golgi localization reveals differential intra-Golgi trafficking of secretory cargoes. Mol. Biol. Cell. 27, 848-61 (2016).

54. M. Schifferer, D. A. Yushchenko, F. Stein, A. Bolbat, C. Schultz, A Ratiometric Sensor for Imaging Insulin Secretion in Single $\beta$ Cells. Cell Chem. Biol. 24, 525-531.e4 (2017).

55. S. Schmidt, M. Mo, F. M. Heidrich, A. Ćelić, B. E. Ehrlich, C-terminal Domain of 44896 (2011).

56. G. Dodson, D. Steiner, The role of assembly in insulin's biosynthesis. Curr. Opin. Struct. Biol. 8, 189-94 (1998).

57. K. Lemaire, M. A. Ravier, A. Schraenen, J. W. M. Creemers, R. Van de Plas, M. Granvik, Schuit, Insulin crystallization depends on zinc transporter ZnT8 expression, but is not required for normal glucose homeostasis in mice. Proc. Natl. Acad. Sci. U. S. A. 106, 14872-7 (2009).

58. J. L. Vinkenborg, T. J. Nicolson, E. A. Bellomo, M. S. Koay, G. A. Rutter, M. Merkx, 
Genetically encoded FRET sensors to monitor intracellular Zn2+ homeostasis. Nat. Methods. 6, 737-40 (2009).

59. S. Obermüller, F. Calegari, A. King, A. Lindqvist, I. Lundquist, A. Salehi, M. Francolini, P.

Rosa, P. Rorsman, W. B. Huttner, S. Barg, Defective secretion of islet hormones in chromogranin-B deficient mice. PLoS One. 5, e8936 (2010).

60. J. von Blume, A.-M. Alleaume, C. Kienzle, A. Carreras-Sureda, M. Valverde, V. Malhotra, Cab45 is required for Ca2+-dependent secretory cargo sorting at the trans-Golgi network. J. Cell Biol. 199, 1057-1066 (2012). -independent glucose-stimulated insulin secretion. Diabetes. 49, 424-30 (2000).

62. N. Beuret, H. Stettler, A. Renold, J. Rutishauser, M. Spiess, Expression of Regulated

63. E. Gomes, J. Shorter, The molecular language of membraneless organelles. J. Biol. Chem. 294, 7115-7127 (2019).

64. T. J. Nott, E. Petsalaki, P. Farber, D. Jervis, E. Fussner, A. Plochowietz, T. D. Craggs, D.

65. G. Griffiths, K. Simons, The trans Golgi network: sorting at the exit site of the Golgi complex. Science (80-. ). 234, 438-443 (1986).

66. I. Mellman, R. Fuchs, A. Helenius, Acidification of the endocytic and exocytic pathways. Annu. Rev. Biochem. 55, 663-700 (1986).

67. R. G. W. Anderson, L. Orci, A view of acidic intracellular compartments. J. Cell Biol. 106, 539-543 (1988). 
718

719

720

721

722

723

724

725

726

727

728

729

730

731

732

733

734

735

736

737

738

739

740

741

742

743

68. J. Tooze, S. A. Tooze, Clathrin-coated vesicular transport of secretory proteins during the formation of ACTH-containing secretory granules in AtT20 cells. J. Cell Biol. 103, 839-850 (1986).

69. Z. A. Syed, L. Zhang, D. T. Tran, C. K. E. Bleck, K. G. Ten Hagen, bioRxiv, in press, doi:10.1101/2021.08.16.456250.

70. R. Kuliawat, P. Arvan, Distinct molecular mechanisms for protein sorting within immature secretory granules of pancreatic beta-cells. J. Cell Biol. 126, 77-86 (1994).

71. M. Montero-Hadjadje, S. Elias, L. Chevalier, M. Benard, Y. Tanguy, V. Turquier, L. Galas, L. Yon, M. M. Malagon, A. Driouich, S. Gasman, Y. Anouar, Chromogranin A promotes peptide hormone sorting to mobile granules in constitutively and regulated secreting cells. Role of conserved N- and C-terminal peptides. J. Biol. Chem. 284, 12420-12431 (2009).

72. H. H. Gerdes, P. Rosa, E. Phillips, P. A. Baeuerle, R. Frank, P. Argos, W. B. Huttner, The primary structure of human secretogranin II, a widespread tyrosine-sulfated secretory granule protein that exhibits low pH- and calcium-induced aggregation. J. Biol. Chem. 264, 12009-12015 (1989).

73. R. El Meskini, L. Jin, R. Marx, A. Bruzzaniti, J. Lee, R. Emeson, R. Mains, A signal sequence is sufficient for green fluorescent protein to be routed to regulated secretory granules. Endocrinology. 142, 864-73 (2001).

74. S. Fargali, A. L. Garcia, M. Sadahiro, C. Jiang, W. G. Janssen, W. Lin, V. Cogliani, A. Elste, S. Mortillo, C. Cero, B. Veitenheimer, G. Graiani, G. M. Pasinetti, S. K. Mahata, J. W. Osborn, G. W. Huntley, G. R. Phillips, D. L. Benson, A. Bartolomucci, S. R. Salton, The granin VGF promotes genesis of secretory vesicles, and regulates circulating catecholamine levels and blood pressure. FASEB J. 28, 2120-2133 (2014).

75. O. Beutel, R. Maraspini, K. Pombo-García, C. Martin-Lemaitre, A. Honigmann, Phase Separation of Zonula Occludens Proteins Drives Formation of Tight Junctions. Cell. 179, 923-936.e11 (2019). 
76. D. Milovanovic, Y. Wu, X. Bian, P. De Camilli, A liquid phase of synapsin and lipid vesicles. Science. 361, 604-607 (2018).

77. D. S. W. Protter, B. S. Rao, B. Van Treeck, Y. Lin, L. Mizoue, M. K. Rosen, R. Parker, Intrinsically Disordered Regions Can Contribute Promiscuous Interactions to RNP Granule Assembly. Cell Rep. 22, 1401-1412 (2018).

78. M. Hosaka, T. Watanabe, Y. Sakai, Y. Uchiyama, T. Takeuchi, Identification of a Chromogranin A Domain That Mediates Binding to Secretogranin III and Targeting to Secretory Granules in Pituitary Cells and Pancreatic $\beta$-Cells. Mol. Biol. Cell. 13, 3388-3399

79. S. Alberti, A. Gladfelter, T. Mittag, Considerations and Challenges in Studying Liquid-Liquid Phase Separation and Biomolecular Condensates. Cell. 176, 419-434 (2019).

80. K. J. Day, G. Kago, L. Wang, J. B. Richter, C. C. Hayden, E. M. Lafer, J. C. Stachowiak, Liquid-like protein interactions catalyse assembly of endocytic vesicles. Nat. Cell Biol. 23,

81. C. S. Scheve, P. A. Gonzales, N. Momin, J. C. Stachowiak, Steric Pressure between

82. D. J. Busch, J. R. Houser, C. C. Hayden, M. B. Sherman, E. M. Lafer, J. C. Stachowiak,

83. W. T. Snead, C. C. Hayden, A. K. Gadok, C. Zhao, E. M. Lafer, P. Rangamani, J. C. E3267 (2017).

84. T. K.-H. Hecht, B. Blank, M. Steger, V. Lopez, G. Beck, B. Ramazanov, M. Mann, V. Tagliabracci, J. von Blume, Fam20C regulates protein secretion by Cab45 phosphorylation. J. Cell Biol. 219 (2020), doi:10.1083/jcb.201910089.

85. K. E. Rohli, C. K. Boyer, S. C. Bearrows, M. R. Moyer, W. S. Elison, C. J. Bauchle, S. E. 
Blom, C.-L. Yu, M. R. Pope, J. Zhang, Y. Wang, S. B. Stephens, bioRxiv, in press, doi:10.1101/2021.09.22.461417.

772 86. Z. Li, I. P. Michael, D. Zhou, A. Nagy, J. M. Rini, Simple piggyBac transposon-based mammalian cell expression system for inducible protein production. Proc. Natl. Acad. Sci. U. S. A. 110, 5004-5009 (2013).

87. G. Joshi, Y. Chi, Z. Huang, Y. Wang, A $\beta$-induced Golgi fragmentation in Alzheimer's disease enhances A $\beta$ production. Proc. Natl. Acad. Sci. 111, E1230-E1239 (2014).

88. D. Tang, Y. Xiang, Y. Wang, Reconstitution of the cell cycle-regulated golgi disassembly and reassembly in a cell-free system. Nat. Protoc. 5, 758-772 (2010). 


\section{Acknowledgments}

795 We highly appreciate constructive discussions with Christopher Burd, Xiaolei Su, Jonathan Bogan

796 and James Rothman. We want to thank Cedric Asensio for the INS1 832/13 cells. We would like

797 to thank Charlotte Ford and Mai Ly Tran for proofreading and discussion of the manuscript. Julia

798 von Blume is funded by a Yale-start up grant and by the National Institute of General Medical

799 Sciences of the United States National Institutes of Health under the award number GM134083-

800 01, an Administrative Supplement 3R01GM134083-03S1 and a Project and Feasibility award

801 from Yale Diabetic Research Center (GR112420). This work was also supported by startup funds

802 provided by the Fraternal Order of Eagles Diabetes Research Center, University of lowa to S.B.S.,

803 Department of Defense CDMRP grant PR190353 to S.B.S., and a National Institutes of Health

804 Predoctoral Training Grant T32GM008629, PI Daniel Eberl to K.E.R.

805

806 Declaration of Interest

807 We have no Declaration of Interest

808

809

810 


\section{Main Figure Titles and Legends}

812 Figure 1: Insulin is distributed in dynamic punctate structures at the Golgi apparatus

813 A) Representative images from a single slice from a confocal image obtained from INS1 832/13

814 cells stained with the Golgi resident protein, Cab45 (green), which outlines the Golgi regions and

815 insulin (pan-insulin antibody; red). Note the punctate structures of proinsulin seen in the

816 perinuclear Golgi region. B) A schematic description of a pulse-chase assay in INS1 832/13 cells

817 stably expressing SNAP-tagged proinsulin. Cells are initially incubated with a non-fluorescent

818 blocking probe to mask the existing proteins in the cells. After 2 hours, cells are labeled with SNAP

819505 and CLIP-TMR to mark the newly synthesized proteins (20 mins). After three washes in

820 growth medium, cells are fixed immediately to monitor the pulse of new synthesized proinsulin

821 arriving at the Golgi apparatus. C) Representative images from a single slice from a confocal

822 image from INS1 832/13 cells expressing SNAP-tagged insulin (red) monitoring the insulin pulse

823 arriving at the Golgi apparatus identified by the cis-Golgi marker GM130 (green). D) INS1 832/13

824 cells were immunostained for insulin (pan-insulin antibody; green), TGN38 (magenta) and

825 counterstained with DAPI (blue). The middle image demonstrates 3D-rendering of the TGN38

826 volume mask which was used for image segmentation to specifically examine insulin staining

827 within the TGN (right image). E) A panel of electron micrographs from mouse islets demonstrating

828 condensed structures within the Golgi lumen. F) Representative images from a single slice from

829 a confocal image of INS832/13 cells stained with the insulin processing enzyme protein

830 convertase 2 (PC2; green) and insulin (pan-insulin antibody; red). Note the colocalization of

831 proinsulin puncta with PC2 at the Golgi apparatus which is outlined in the merge image using

832 dashed lines. G) A panel of images extracted from a movie from live imaging of INS832/13 cells

833 transiently transfected with RINS1, a fluorescent insulin reporter construct. Dynamics of the

834 punctate structures (pink dashed line) are captured in the image sequence where structures

835 undergo fission or fusion events. Images shown here are single confocal slices upon imaging in 
836 the conventional confocal mode (i) or in the airy scan confocal mode (ii). Images have been

837 smoothened using the function in ImageJ for visual representation purposes.

838 Figure 2: CGs undergo LLPS in vitro

839 A) Plots of CGB (left) and CGA (right) generated using PONDR depicting disordered regions in 840 the proteins. While N-terminal half of CGB is completely disordered, almost $90 \%$ of CGA shows 841 disorder when analyzed using the VL-XT algorithm. Images below show the structural predictions 842 of CGB and CGA using Alpha fold. B) Scheme used for purifying GFP and 6x-His tagged CGA or 843 CGB, respectively. Stable lines expressing CGB-GFP and CGA-GFP under a doxycycline 844 inducible promoter are treated with doxycycline and the calcium ionophore A23187 to induce 845 secretion of the respective proteins in serum free medium, which is then used for purification using 846 Ni-NTA affinity columns. C) Coomassie stained gel depicting purified CGB-GFP. The images 847 show droplets of CGB-GFP (left) at $10 \mu \mathrm{M}$ protein concentration at pH 6.1 without crowding agent.

848 The same concentrations of super folder-GFP does not form droplets at $\mathrm{pH} 6.1$ (right). D) 849 Coomassie stained gel depicting purified CGA-GFP. Images showing different droplets of CGA850 GFP at different protein concentrations at $\mathrm{pH} 6.1$ in presence of $5 \%$ PEG 8000 . Note that the size 851 of the condensates decreases with decreasing protein concentration. E) A panel of images 852 extracted from a movie showing the biophysical behavior of CGB-GFP $(2.5 \mu \mathrm{M})$ droplets induced 853 by $1 \%$ PEG8000. Two droplets, which come in proximity undergo fusion and the larger droplet 854 subsequently relaxes into a spherical shape. F) A panel of images monitoring recovery of 855 fluorescence of CGB-GFP droplets after bleaching a small region within the droplets. Note the 856 rapid recovery of fluorescence (more than 60\%) in the bleached region within a minute. G) Graph 857 quantifying the fluorescence recovery in time. Data represented as mean +/- s.d. (error blanket) 858 from eight independent droplets. 
861 A) Representative images of solutions containing CGA-GFP (i, ii) or CGB-GFP (iii; iv) buffered at 862 either pH 6.1 (I, iii) or pH 7.3 (ii, iv). Droplet formation occurs at pH 6.1 and not at pH 7.3. Droplets 863 of CGA-GFP were induced at $4 \mu \mathrm{M}$ protein concentration in presence of $5 \%$ dextran, while $10 \mu \mathrm{M}$

864 CGB-GFP formed droplets without crowding agents at pH 6.1. B) Representative images of CGB-

865 GFP $(2.5 \mu \mathrm{M})$ protein without any divalent cation (minus) or in presence of $20 \mathrm{mM}$ magnesium, manganese, calcium, and zinc respectively. CGB-GFP solution (approximately $10 \mu \mathrm{M}$ concentration) was centrifuged to preclear of existing droplets and diluted to a final concentration of $2.5 \mu \mathrm{M}$. While, magnesium, manganese and calcium induce CGB-GFP droplets, zinc induces formation of insoluble aggregates. In terms of droplet formation potential manganese > calcium > magnesium. C) Representative images of CGB-GFP $(2.5 \mu \mathrm{M})$ in presence of different

871 concentrations of zinc. At high concentrations zinc induces formation of insoluble aggregates but

872 at low concentration it induces CGB-GFP droplets. D, E) Snapshots captured at different time

873 points after photobleaching a region within a calcium induced CGB-GFP droplet (top panel) or a

874 zinc induced CGB-GFP aggregate are shown in D. While there is more than $60 \%$ fluorescence

875 recovery within the bleached region in the calcium induced droplet, recovery within the bleached

876 region in the aggregate is only $10 \%$ as seen in the graph in E. Red curve denotes recovery of

877 calcium induced droplets and blue curve denotes zinc induced aggregates. Data is represented

878 as mean +/- s.d. (error blanket) from at least six droplets/aggregates. F) Images on the left side

879 show a single plane from an airy-scan confocal image of the CGB-GFP condensate at pH 5.2

880 before (top panel) and after addition of $20 \mathrm{mM}$ zinc (bottom panel). Zinc induces aggregation

881 within a preformed droplet and is accompanied by shrinkage in volume as seen from the 3D-

882 projections on the right. G, H) A panel of images from a FRAP experiment involving bleaching of

883 a small region within CGB-GFP droplets formed at pH 5.2 (top panel) and after treating them with

884 zinc (bottom panel). Graph in $\mathrm{H}$ shows the comparison of FRAP recovery curves of CGB-GFP 
droplets at $\mathrm{pH} 5.2$ with (blue curve) and prior to zinc addition (red curve). While the fluorescence recovery in the bleached region within CGB-GFP droplets without zinc addition is approximately $50 \%$, droplets get hardened after zinc addition and recovery is approximately $15 \%$. Data is represented as mean +/- s.d. (error blanket) from at least seven droplets in each condition.

\section{Figure 4: Proinsulin co-traffics with CGB in vivo and is recruited to droplets in vitro}

A) Schematic depiction of dual pulse chase experiment in INS1 832/13 cells expressing SNAP a non-fluorescent blocking probe to mask the existing proteins in the cells. After 2 hours, cells are incubated with medium containing with SNAP 505 and CLIP-TMR to label the newly synthesized proteins (20 mins). After three washes in growth medium, cells are fixed immediately ( $0 \mathrm{~h}$ chase) when majority of the cargo is at the Golgi apparatus or after a chase of 2 hours where most of the cargo has moved to the SG in the cytoplasm. B) Top panel shows confocal images form INS832/13 cells expressing SNAP tagged insulin (proCpepSNAP; green) and CLIP tagged CGB in red and fixed immediately after labeling with fluorescent probes, SNAP-505 and CLIP-TMR to monitor the Golgi resident (peri-nuclear) pool of the proteins. Bottom panels show images after a 2-hour chase and the arrows point to some of the colocalizing structures which are cytoplasmic SGs. C-E) INS832/13 cells fixed and labeled with antibodies to insulin in or CGB (A), CGB (B) and SCG3 (C) in green. Insulin puncta at the Golgi apparatus in the perinuclear region, outlined using the dashed lines in the merge colocalize with each of the granin proteins. For CGB and CGA, images are a single slice from a confocal stack and in case of SCG3, an average projection from three consecutive slices from a confocal image. F) CGB-GFP (2.5 $\mu \mathrm{M}$; green) was mixed with mcherry tagged proinsulin $(1 \mu \mathrm{M}$; red) in (i) and droplets were induced at pH 6.1 using $3 \%$ PEG 8000. Tagged proinsulin gets recruited to the CGB-GFP droplets as evident from the colocalization image. When GFP $(2.5 \mu \mathrm{M}$; green) is mixed with mCherry tagged proinsulin $(1 \mu \mathrm{M}$; 
910 indicating that GFP or mCherry-proinsulin are incapable of forming droplets on their own at these

911 concentrations.

912 Figure 5: Ectopic expression of soluble secreted proteins in INS832/13 cells results in their

913 routing to insulin granules.

914 A-F) INS1 832/13 cells were immunostained for insulin (pan-insulin antibody; green), TGN38

915 (shown in Supp Figure 4A), CPE (A, D), M6PR (B, E), or IGF2R (C, F). (A-C) Image segmentation

916 of the TGN38 volume was used to identify Golgi-staining regions. (D-F) Line intensity profiles of

917 the Golgi staining regions for each protein are shown. G, H) Representative images from

918 INS832/13 cells expressing LyzC-GFP (E; green) or EqSOL-GFP (F; green) and stained with

919 insulin antibody (red) to observe the localization of the ectopically expressed proteins with respect

920 to insulin granules. Images are average projections from two slices from a confocal stack.

921 Arrowheads point to cytoplasmic insulin granules which also shows the presence of LyzC-GFP

922 and EqSOL-GFP respectively, in E and F. I) Representative images from INS1 832/13 cells stably

923 expressing CatD-GFP (green) and labeled with CGB antibody to observe the localization of

924 ectopically expressed CatD-GFP with respect to SGs. Images are average projections from two

925 slices from a confocal stack. Arrowheads point to some of the cytoplasmic SG, which shows

926 colocalization of CGB and CatD-GFP. J) Representative images from INS832/13 expressing HA-

927 tagged version of the calcium ATPase, SPCA1 (green) and stained using CGB antibody (red).

928 Images are a single slice from a confocal stack. Note that overexpressed SPCA1 remains

929 localized at the Golgi apparatus with no signal seen from the CGB containing SGs. K)

930 Representative images from HeLa cells stably expressing CGA-GFP and transfected with LyzC-

931 RFP. Images are a single slice from a confocal stack imaged in the airy-scan mode. The

932 arrowheads point to some of the ectopic granule-like structures seen in HeLa cells upon

933 expression of CGA-GFP. Note that LyzC-RFP gets routed to these ectopic granule-like structures.

934 L) Western blot at the top shows bands for LyzC-GFP, probed using $\alpha-G F P$ antibody, in 
935 supernatant and lysates from INS1 832/13 cells stable expressing SNAP-tagged proinsulin. The

936 basal condition represents cells grown in $3 \mathrm{mM}$ glucose in serum free medium and the stimulated

937 condition represents cells grown in $15 \mathrm{mM}$ glucose in serum free medium, also containing $35 \mathrm{mM}$

938 potassium chloride. Note the stronger band intensity in the supernatant in stimulated condition

939 compared to the basal condition, although the levels in cell lysates are the same. The blot in the

940 bottom left detects the presence of SNAP tagged C-peptide, probed using a-SNAP antibody,

941 which is used as a proxy to measure insulin secretion. Again, the signal intensity of the band is

942 stronger in stimulated condition as compared to the basal condition. The blot on the bottom right

943 depicts actin bands in cell lysates obtained from basal and stimulated conditions. The graph

944 quantifies secretion of LyzC-GFP normalized with levels in cell lysates in basal and stimulated

945 conditions. Data is represented as mean +/- s.d. from three independent experiments. ${ }^{*} p<0.05$.

\section{Figure 6: Client recruitment in vitro}

947 A, B) CGB-GFP (2.5 $\mu \mathrm{M}$; green) was mixed with Cy3-tagged LyzC (1 $\mu \mathrm{M}$; red) and was

948 subsequently followed by addition of $20 \mathrm{mM}$ calcium to induce liquid like droplets or with $20 \mathrm{mM}$

949 zinc to induce aggregates. While calcium induced CGB-GFP droplets recruit Cy3-LyzC, the zinc

950 induced aggregates fail to recruit it. Bar graph is B quantifies the ratio of intensities in Cy3 v/s

951 GFP channel, imaged at same acquisition settings, to monitor recruitment of LyzC in relation to

952 amount of CGB in the droplet (red) v/s aggregate (blue). Data is represented as mean +/- s.d.

953 from at least thirty droplets or regions within an aggregate. ${ }^{* * *} p<0.001$. C, D) CGB-GFP $(2.5 \mu \mathrm{M}$;

954 green) was mixed with Cy3-tagged LyzC (1 $\mu \mathrm{M}$; red; top panel) or with Cy3-tagged lgg $(1 \mu \mathrm{M}$;

955 red; bottom panel) and droplet formation was induced using 3\% PEG8000 to monitor the

956 recruitment of these cargoes into the CGB droplets. While LyzC, which is $14.3 \mathrm{kDa}$ in size shows

957 a uniform recruitment within the CGB droplet, $150 \mathrm{kDa} \operatorname{lgG}$, only shows recruitment at the edges

958 of the CGB droplets. The images are a single slice of a confocal image to image through the cross

959 section of a droplet from the center and were smoothened for representation purposes using the 
960 function in Image J. Graph in D, shows line scans in the Cy3 channel again taken approximately

961 from the center of the droplet along the longest axis. For Cy3-LyzC, the intensity continues to rise

962 as we move from the edge to the center with plateauing in the center of the droplet, while for Cy3-

963 Igg there is a sharp decline in intensity in the center of the droplet, consistent with their recruitment

964 profile. E) CGB-GFP $(2.5 \mu \mathrm{M}$; green) was mixed with Cy3-tagged CatD $(1 \mu \mathrm{M}$; red $)$ and droplet

965 formation was induced using 3\% PEG8000 to monitor the recruitment of clients into the

966 condensates. Note that Cy3-CatD shows a strong recruitment to the droplets.

\section{Figure 7: In vitro and in vivo phenotypes associated with truncation mutants of CGB}

968 A) Plots of CGB generated using PONDR (VL-XT algorithm) depicting disordered regions in the 969 protein. Based on the PONDR scores, amino acids 46-334 are highly unstructured, thus showing 970 a high degree of disorder compared to residues 335-677. B) Representative images showing a 971 comparison of condensates of full length CGB-GFP, CGB_N term-GFP and CGB_C term972 mCherry respectively. Droplet formation was initiated at $\mathrm{pH} 6.1$ with $2 \mu \mathrm{M}$ protein in presence of $9733 \%$ PEG8000. C) Histogram represents the frequency distribution of size of condensates for each 974 of the three proteins. Area was quantified from at least one thousand droplets for each condition.

975 Note that the size of the droplets is larger for CGB-GFP, CGB_N term-GFP compared to CGB_C 976 term-mCherry. D) Representative images of droplet formation obtained upon mixing CGB_N term977 GFP (green) and CGB_C term-mCherry (red). Droplet formation was initiated at pH 6.1 upon 978 mixing $2 \mu \mathrm{M}$ protein of each protein in presence of 3\% PEG8000. CGB_N term-GFP and CGB_C 979 term-mCherry cooperatively form larger droplets together. E) Graph quantifies area occupied by 980 all the droplets in a field of view from a microscopy image. Data was pooled from 6 field of views. 981 CGB-GFP > CGB_N term-GFP > CGB_C term-mCherry. Upon mixing CGB_N term-GFP with 982 CGB_C term-mCherry, there is a restoration in the area covered by the condensates to the levels 983 of the full-length protein. ${ }^{* * *} p<0.001$. F) Representative images of HEK293 cells expressing CGB984 GFP (left), CGB_N term-GFP (middle) and CGB_C term-GFP (right) and induced with doxycycline 
985 for ten hours. Images were taken on a confocal microscope to observe ectopic granule-like

986 structures in HEK293 cells, and the bottom-most plane of the cells plated on the coverslips was

987 imaged. While CGB-GFP and CGB_N term-GFP expression induces formation of ectopic

988 granules in HEK293 cells, much lesser granules are seen upon expression of CGB_C term-GFP.

989 G) Graph quantifies the percentage area occupied by the ectopic granules as a fraction of total

990 cell area. Data was obtained from at least 12 cells pooled from two independent experiments. *

$991 p<0.05,{ }^{* * *} p<0.001$.

992 Figure 8: Effects of salt concentration and acidic amino acids on LLPS of CGB

993 A) Schematic representation of CGB, depicting 5 exons. Patches in red are stretches enriched in 994 acidic amino acids. $S^{*}$ and $Y^{*}$ denote phosphorylation and sulfation respectively on these 995 residues. KR or RK are the dibasic sites in the protein which are predominantly concentrated in 996 the C-terminal half of the protein. B) Representative images of CGB-GFP equilibrated at $\mathrm{pH} 6.1$ 997 in presence of either $150 \mathrm{mM} \mathrm{NaCl}$ (physiological salt; left) or $500 \mathrm{mM} \mathrm{NaCl}$ (high salt; right). 998 Droplet formation is only seen in presence of physiological salt concentration of $150 \mathrm{mM}$, but not 999 seen at high $(500 \mathrm{mM}) \mathrm{NaCl}$ concentrations. C) Representative Coomassie stained image of 1000 mutant form of CGB, CGB_5(ED)/A-GFP to depict its purity. In this mutant the 5 (ED) stretches 1001 have been replaced to alanine. The fluorescence image shows condensates of CGB_5(ED)/A 1002 when equilibrated at $\mathrm{pH} 6.1$ at $10 \mu \mathrm{M}$ protein concentration. D) Comparison of CGB-GFP and 1003 CGB_5(ED)/A-GFP in presence of $20 \mathrm{mM}$ calcium concentrations. Note that at $2.5 \mu \mathrm{M}$ protein 1004 concentration, calcium can induce droplet formation with only CGB-GFP, but now with 1005 CGB_5(ED)/A-GFP. E) Model presented summarizes our findings on the role of LLPS in receptor 1007 TGN, behaving like a "cargo sponge" and recruit clients like proinsulin by the virtue of their relative 1008 abundance to the condensates. Larger molecules which can only attach the condensate from 1009 edges would not be enriched in the CG condensates. Lysosomal hyrolases would be sorted to 
1010 the endolysosomes via the mannose-6-phosphate receptor pathway. However, upon

1011 overexpression, the receptors are saturated and hence owing to their smaller size and high

1012 abundance at the TGN, they get sucked into the CG condensates and hence delivered to the

1013 SGs. As the SGs mature, presence of high zinc concentrations leads to hexamerization of insulin

1014 after its proteolysis. CGs can undergo aggregation and could represent one of the possible

1015 mechanisms for cargo segregation within the SGs.

1016

1017

1018

1019

1020

1021

1022

1023

1024

1025

1026

1027

1028

1029

1030

1031

1032

1033

1034 
bioRxiv preprint doi: https://doi.org/10.1101/2021.12.22.472607; this version posted December 23, 2021. The copyright holder for this preprint (which was not certified by peer review) is the author/funder, who has granted bioRxiv a license to display the preprint in perpetuity. It is made available under aCC-BY-NC-ND 4.0 International license.

Fig1
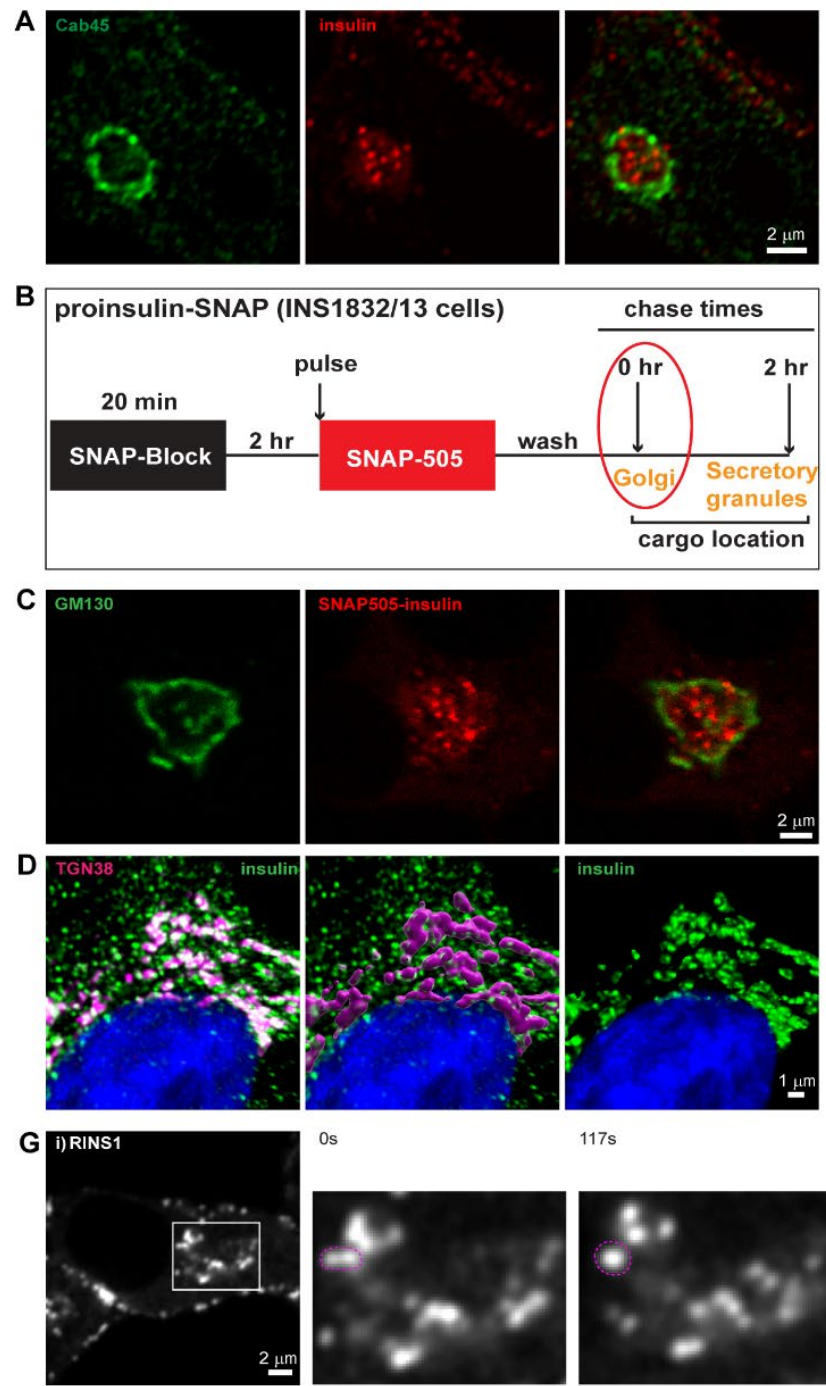

Os

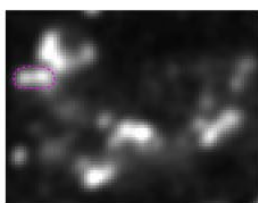

Os



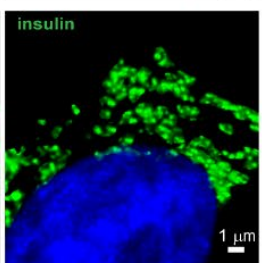

$117 \mathrm{~s}$

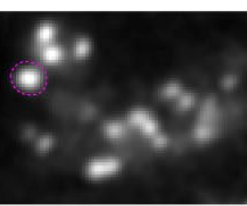

$28 \mathrm{~s}$

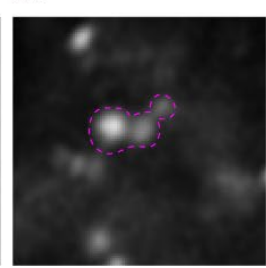

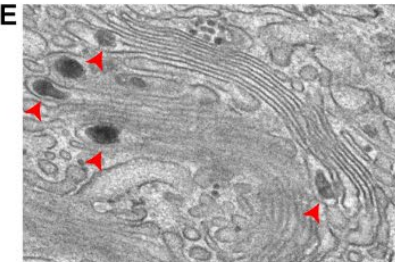


213s

$228 \mathrm{~s}$

$290 \mathrm{~s}$
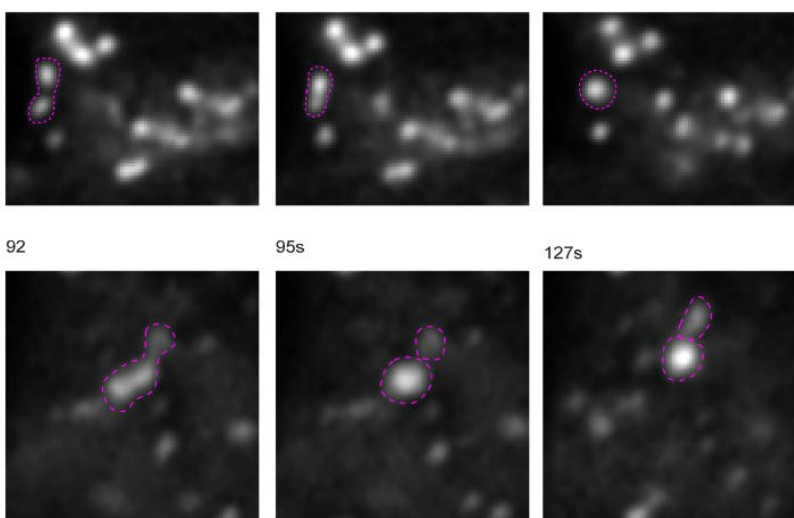
bioRxiv preprint doi: https://doi.org/10.1101/2021.12.22.472607; this version posted December 23, 2021. The copyright holder for this preprint (which was not certified by peer review) is the author/funder, who has granted bioRxiv a license to display the preprint in perpetuity. It is made available under aCC-BY-NC-ND 4.0 International license.

Fig2
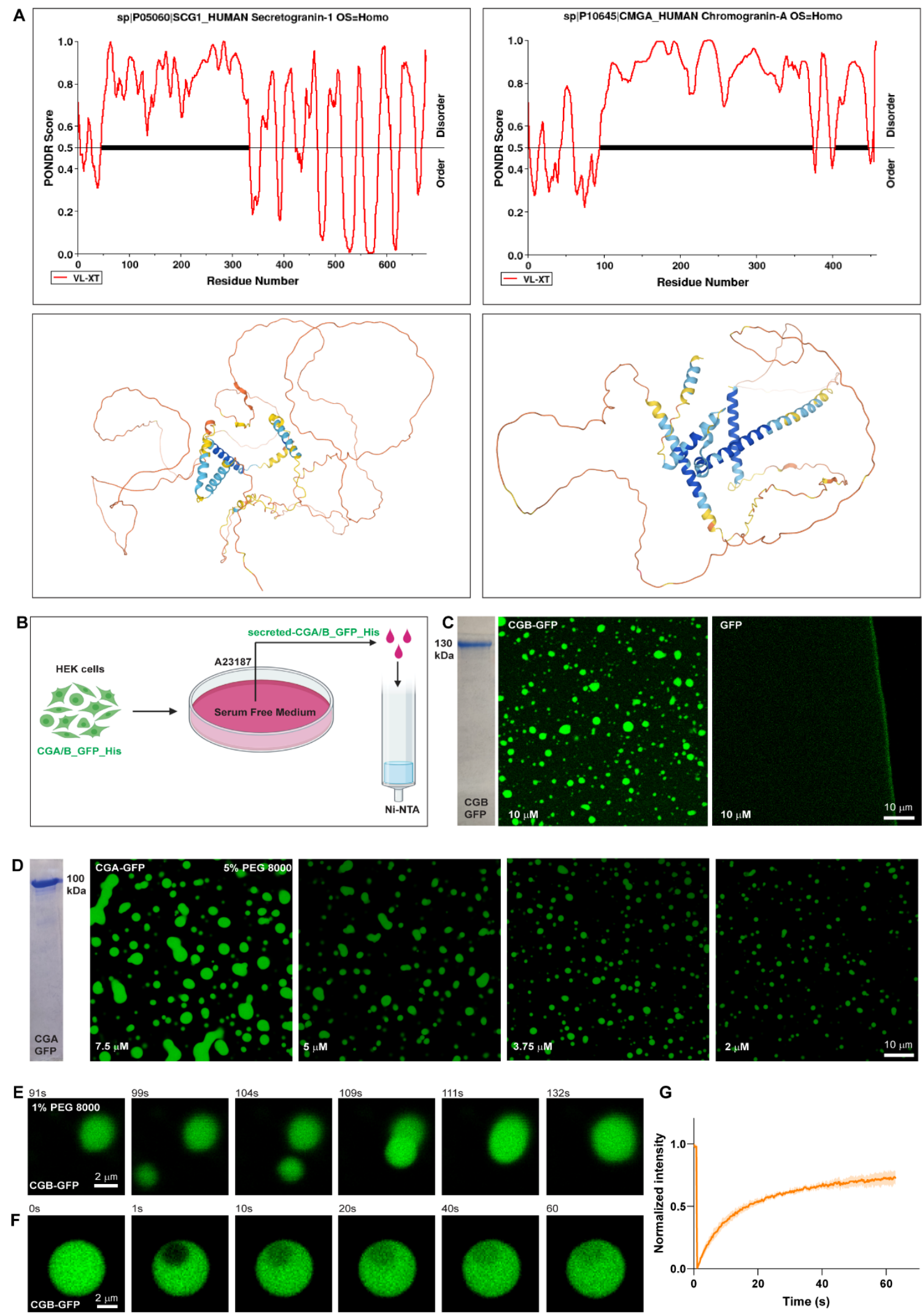
bioRxiv preprint doi: https://doi.org/10.1101/2021.12.22.472607; this version posted December 23, 2021. The copyright holder for this preprint

(which was not certified by peer review) is the author/funder, who has granted bioRxiv a license to display the preprint in perpetuity. It is made available under aCC-BY-NC-ND 4.0 International license.

Fig3
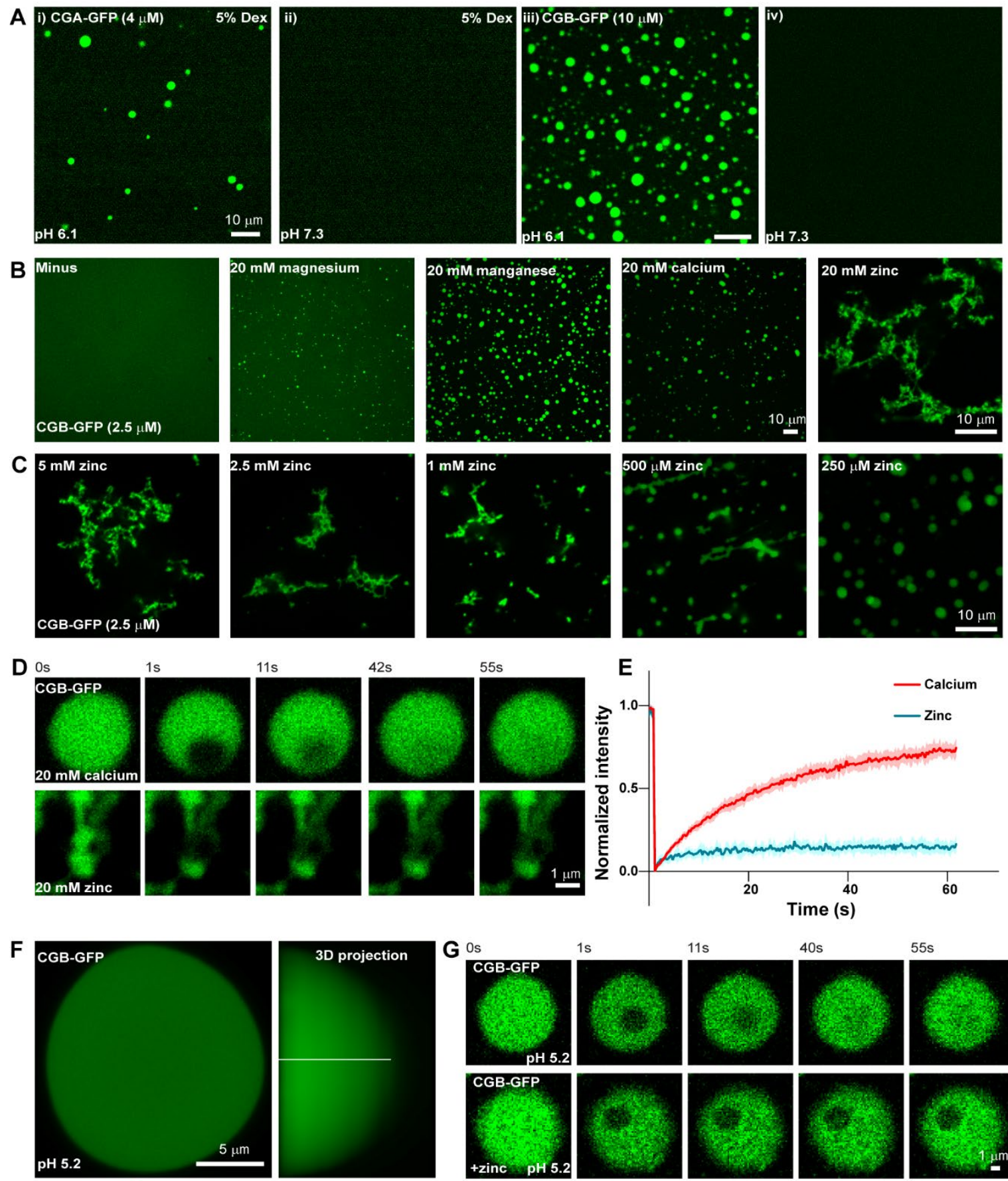

1s $11 \mathrm{~s}$

$40 \mathrm{~s}$
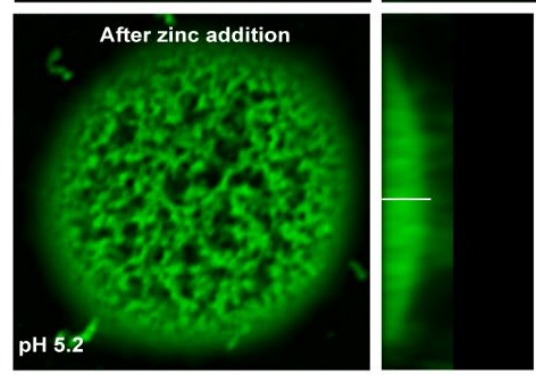

H

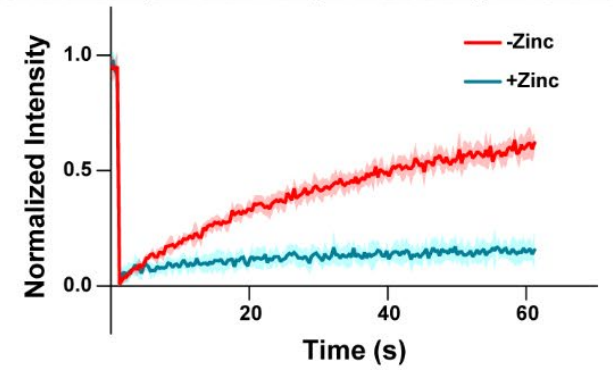


bioRxiv preprint doi: https://doi.org/10.1101/2021.12.22.472607; this version posted December 23, 2021. The copyright holder for this preprint (which was not certified by peer review) is the author/funder, who has granted bioRxiv a license to display the preprint in perpetuity. It is made available under aCC-BY-NC-ND 4.0 International license.

Fig4

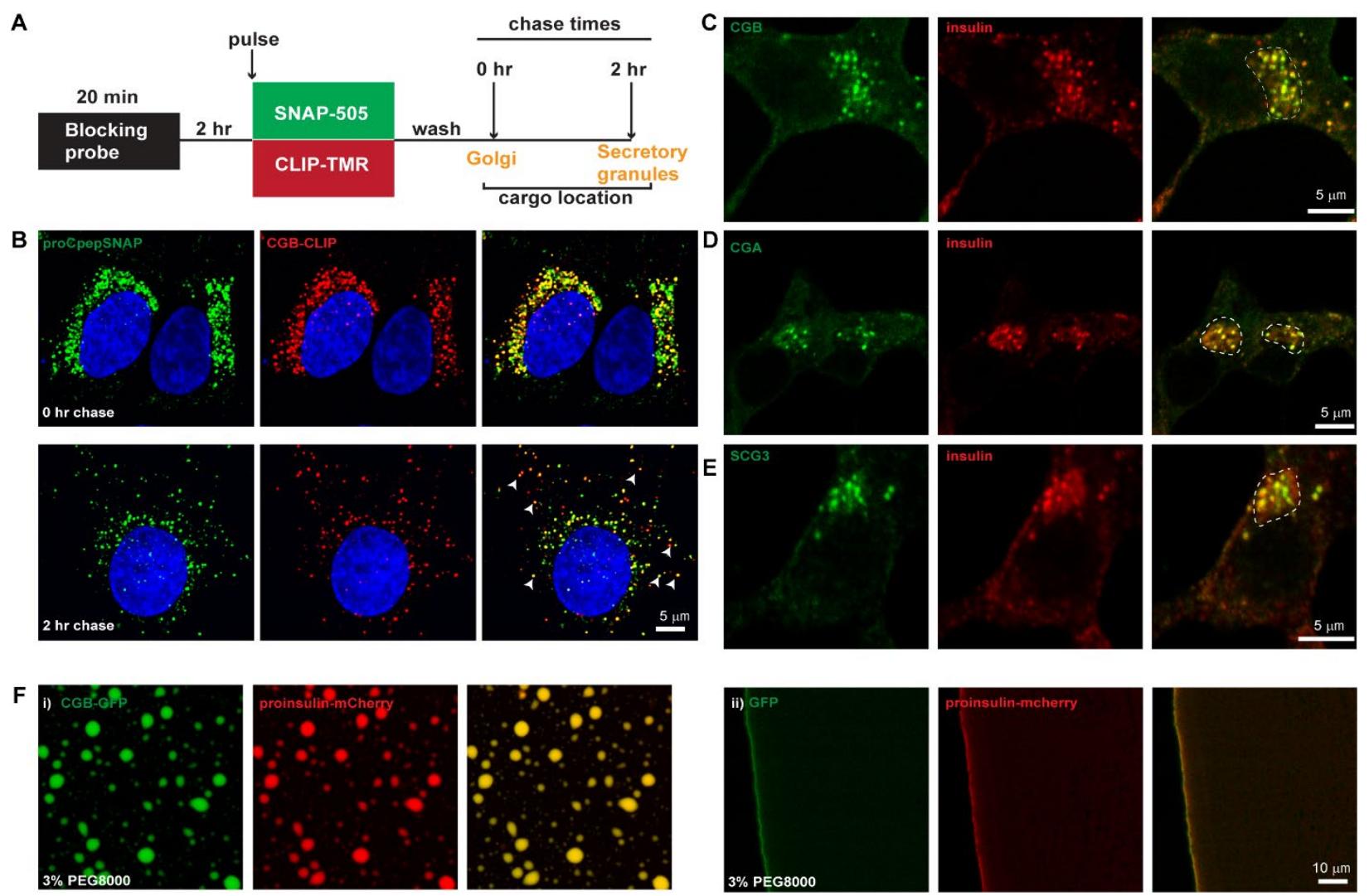


bioRxiv preprint doi: https://doi.org/10.1101/2021.12.22.472607; this version posted December 23, 2021. The copyright holder for this preprint

(which was not certified by peer review) is the author/funder, who has granted bioRxiv a license to display the preprint in perpetuity. It is made available under aCC-BY-NC-ND 4.0 International license.

\section{Fig5}
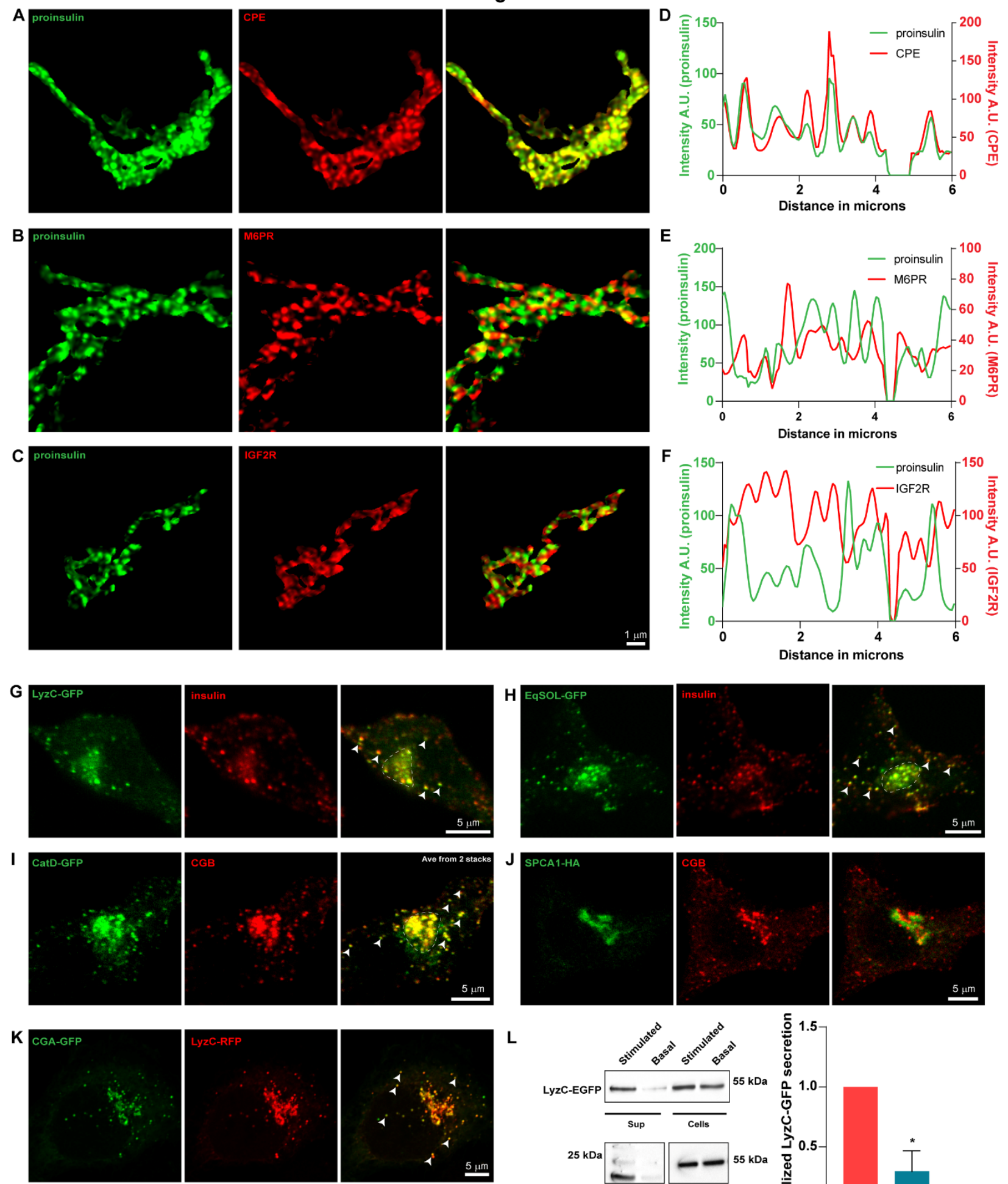
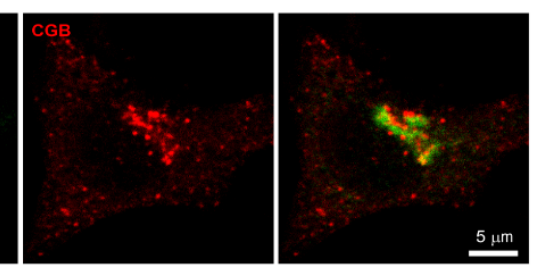

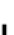
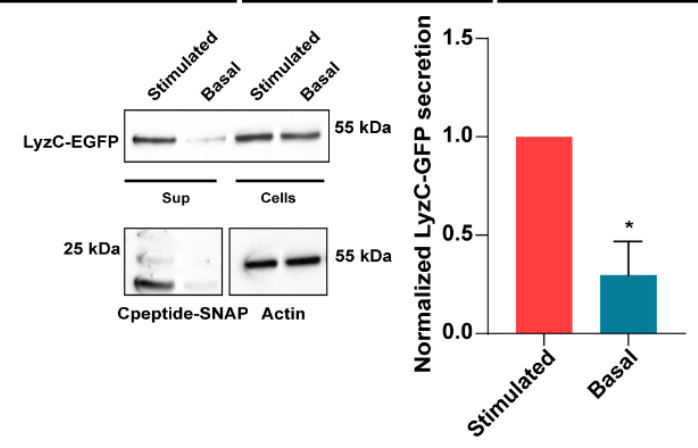
bioRxiv preprint doi: https://doi.org/10.1101/2021.12.22.472607; this version posted December 23, 2021. The copyright holder for this preprint (which was not certified by peer review) is the author/funder, who has granted bioRxiv a license to display the preprint in perpetuity. It is made available under aCC-BY-NC-ND 4.0 International license.

\section{Fig6}
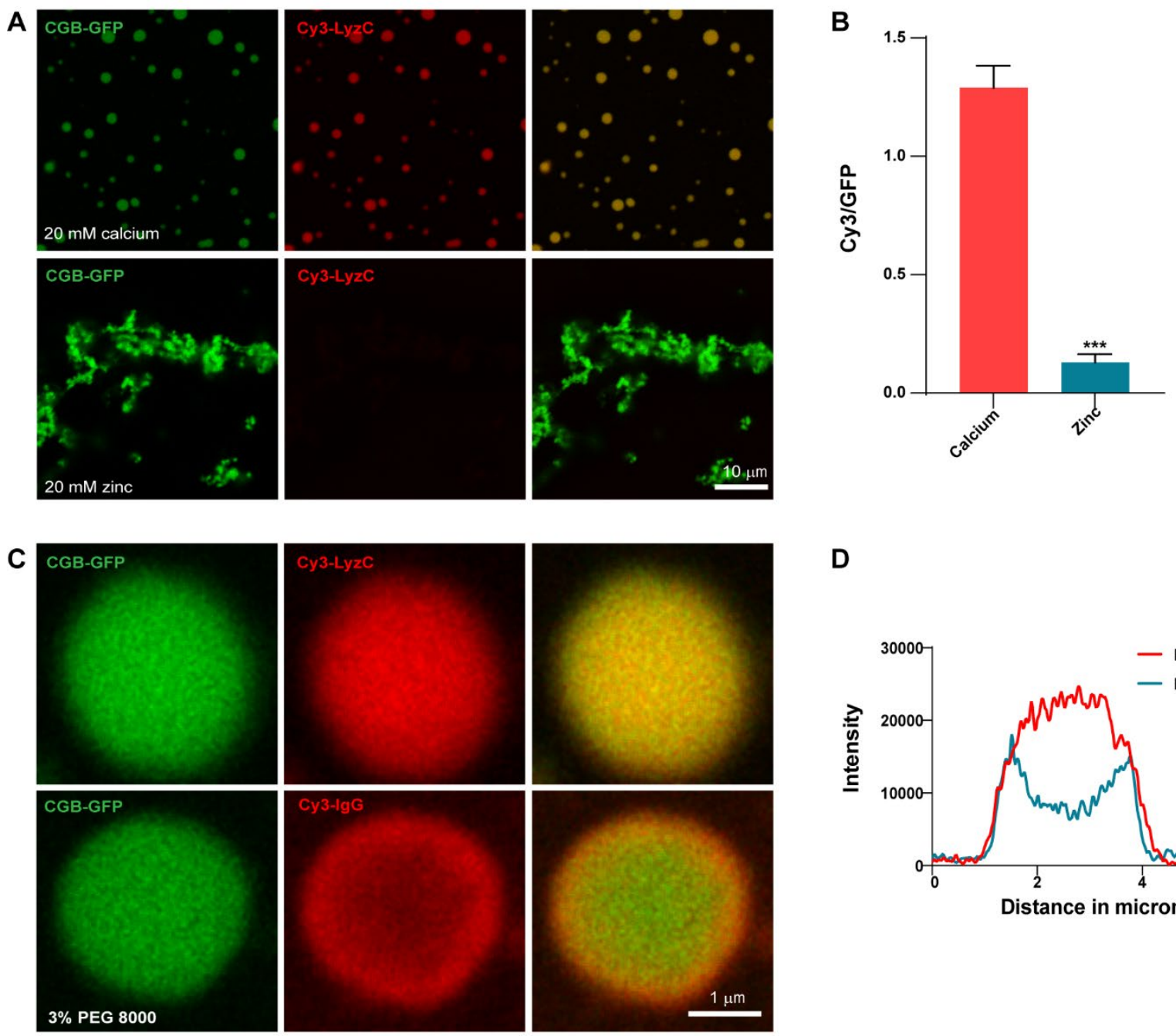

D

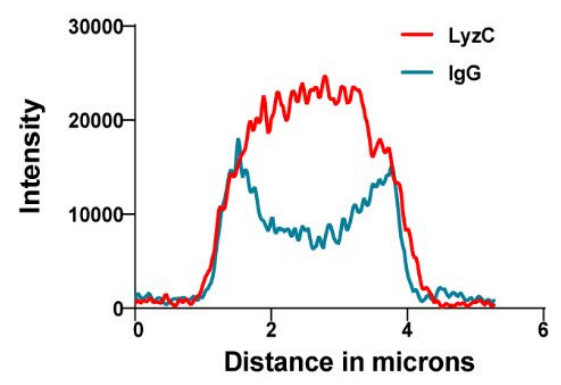

E

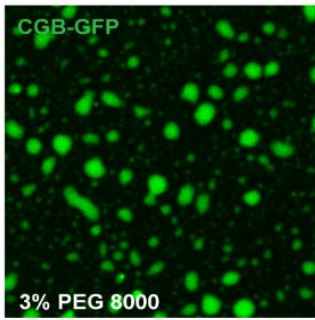

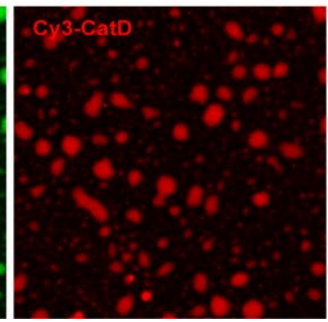

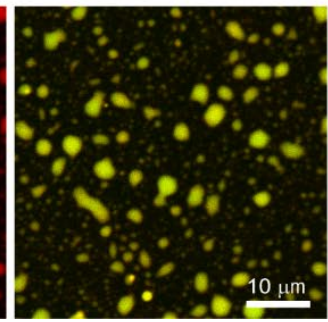


bioRxiv preprint doi: https://doi.org/10.1101/2021.12.22.472607; this version posted December 23, 2021. The copyright holder for this preprint (which was not certified by peer review) is the author/funder, who has granted bioRxiv a license to display the preprint in perpetuity. It is made available under aCC-BY-NC-ND 4.0 International license.

Fig7
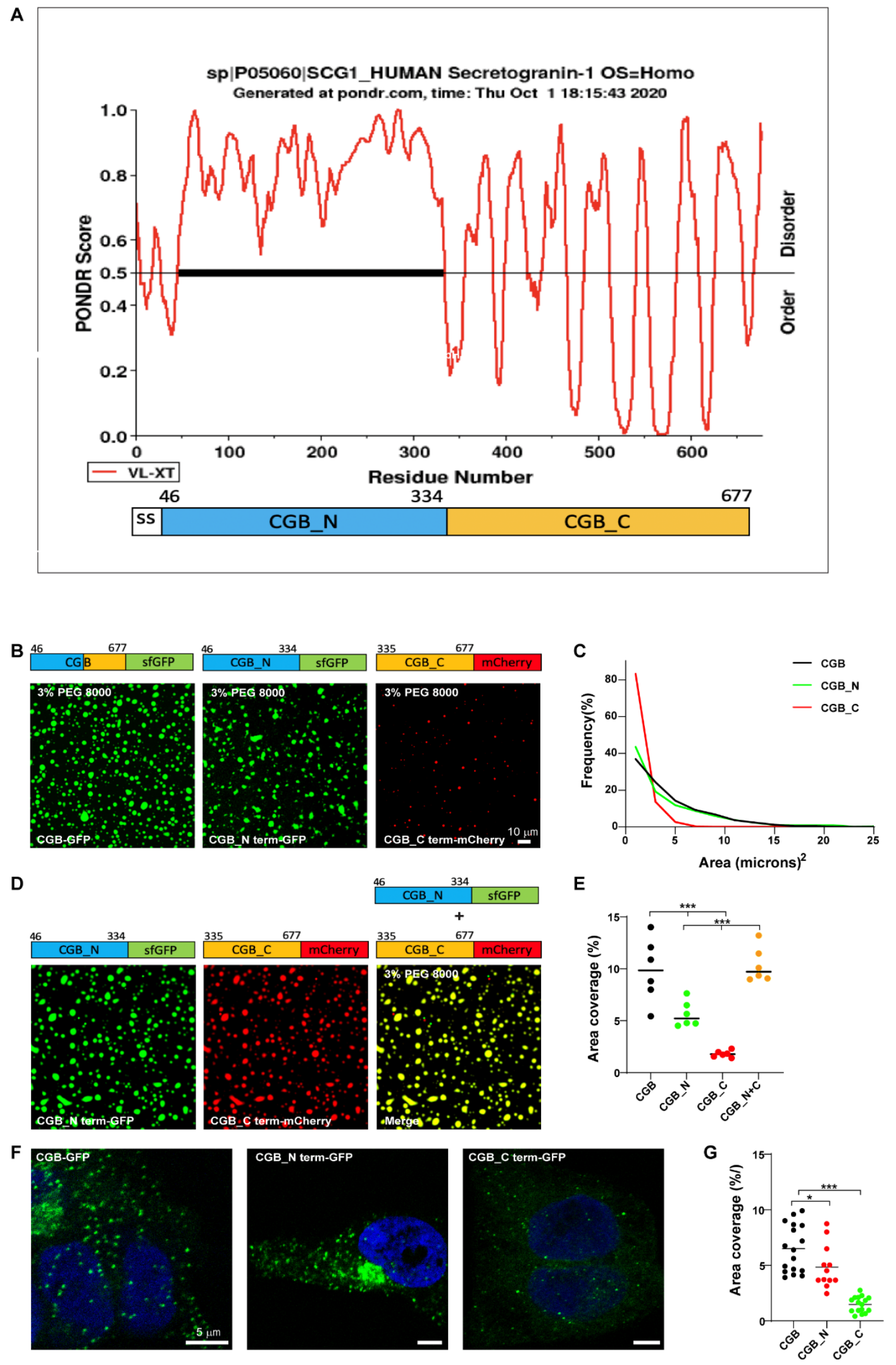
bioRxiv preprint doi: https://doi.org/10.1101/2021.12.22.472607; this version posted December 23, 2021. The copyright holder for this preprint (which was not certified by peer review) is the author/funder, who has granted bioRxiv a license to display the preprint in perpetuity. It is made available under aCC-BY-NC-ND 4.0 International license.

Fig8
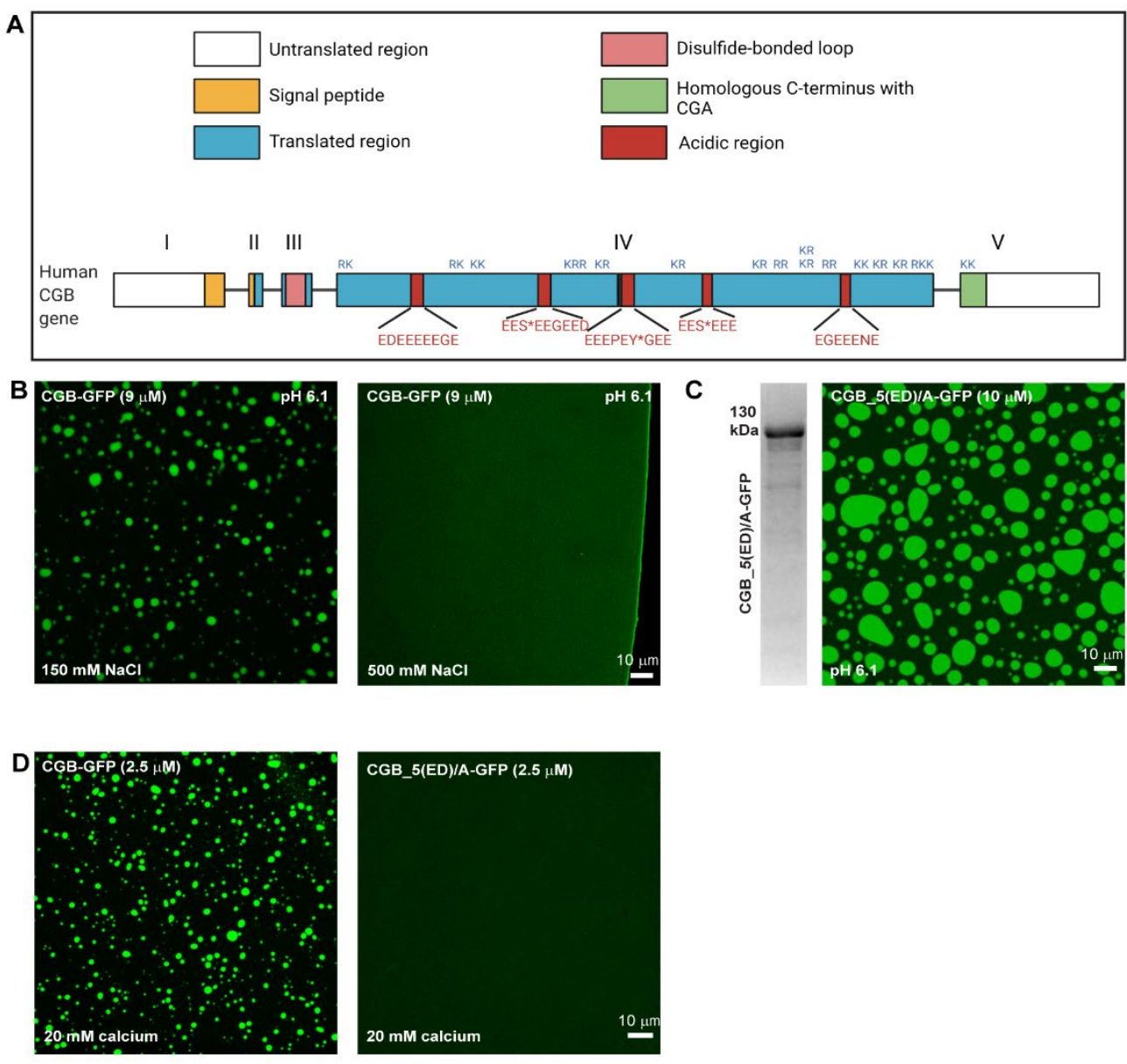

E

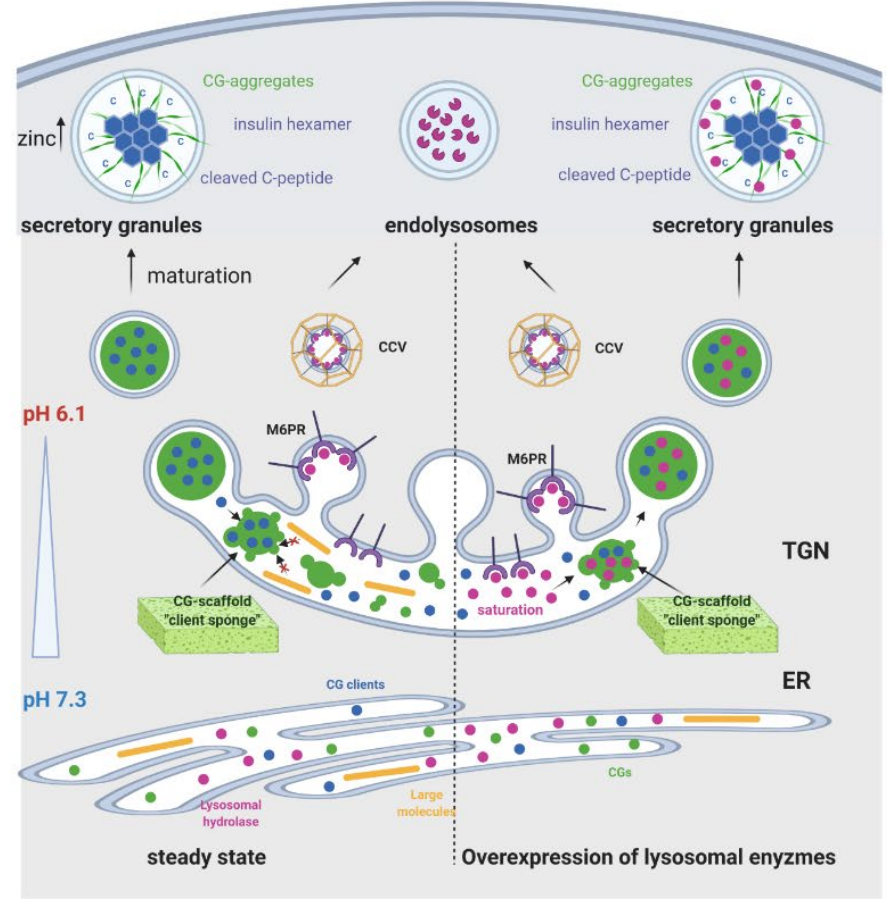

